\title{
Assessment of MISR Cloud Motion Vectors (CMVs) Relative to GOES and MODIS Atmospheric Motion Vectors (AMVs)
}

\author{
Kevin J. Mueller, ${ }^{\text {a Dong L. Wu, }}{ }^{\mathrm{b}}$ Ákos Horváth,${ }^{\mathrm{c}}$ Veljko M. Jovanovic, ${ }^{\mathrm{a}}$ \\ JAN-PETER Muller, ${ }^{\mathrm{d}}$ LARry Di Girolamo, ${ }^{\mathrm{e}}$ Michael J. GARAY,${ }^{\mathrm{a}}$ DAVID J. Diner, ${ }^{\mathrm{a}}$ \\ CATHERINE M. MORONEY, ${ }^{a}$ AND STEVE WANZONG ${ }^{\mathrm{f}}$ \\ ${ }^{\text {a } J e t ~ P r o p u l s i o n ~ L a b o r a t o r y, ~ C a l i f o r n i a ~ I n s t i t u t e ~ o f ~ T e c h n o l o g y, ~ P a s a d e n a, ~ C a l i f o r n i a ~}$ \\ ${ }^{\mathrm{b}}$ NASA Goddard Space Flight Center, Greenbelt, Maryland \\ ${ }^{\mathrm{c}}$ Science and Technology Facilities Council Rutherford Appleton Laboratory, Didcot, United Kingdom \\ d Mullard Space Science Laboratory, University College London, London, United Kingdom \\ ${ }^{\mathrm{e}}$ Department of Atmospheric Sciences, University of Illinois at Urbana-Champaign, Urbana, Illinois \\ ${ }^{\mathrm{f}}$ Cooperative Institute for Meteorological Satellite Studies, University of Wisconsin-Madison, Madison, Wisconsin
}

(Manuscript received 10 March 2016, in final form 16 November 2016)

\begin{abstract}
Cloud motion vector (CMV) winds retrieved from the Multiangle Imaging SpectroRadiometer (MISR) instrument on the polar-orbiting Terra satellite from 2003 to 2008 are compared with collocated atmospheric motion vectors (AMVs) retrieved from Geostationary Operational Environmental Satellite (GOES) imagery over the tropics and midlatitudes and from Moderate Resolution Imaging Spectroradiometer (MODIS) imagery near the poles. MISR imagery from multiple view angles is exploited to jointly retrieve stereoscopic cloud heights and motions, showing advantages over the AMV heights assigned by radiometric means, particularly at low heights $(<3 \mathrm{~km})$ that account for over $95 \%$ of MISR CMV sampling. MISR-GOES wind differences exhibit a standard deviation ranging with increasing height from 3.3 to $4.5 \mathrm{~m} \mathrm{~s}^{-1}$ for a high-quality [quality indicator $(\mathrm{QI}) \geq 80$ ] subset where height differences are $<1.5 \mathrm{~km}$. Much of the observed difference can be attributed to the less accurately retrieved component of CMV motion along the direction of satellite motion. MISR CMV retrieval is subject to correlation between error in retrieval of this along-track component and of height. This manifests as along-track bias varying with height to magnitudes as large as $2.5 \mathrm{~m} \mathrm{~s}^{-1}$. The cross-track component of MISR CMVs shows small $\left(<0.5 \mathrm{~m} \mathrm{~s}^{-1}\right)$ bias and standard deviation of differences $\left(1.7 \mathrm{~m} \mathrm{~s}^{-1}\right)$ relative to GOES AMVs. Larger differences relative to MODIS are attributed to the tracking of cloud features at heights lower than MODIS in multilayer cloud scenes.
\end{abstract}

\section{Introduction}

Atmospheric motion vectors (AMVs), a proxy measure of wind, are indispensable to regional and global numerical weather prediction (NWP) models and analyses. Derived by tracking cloud or water vapor features in satellite imagery, AMVs mitigate critical data gaps in regions that are otherwise observation poor (e.g., the Arctic, Antarctic, and global oceans). However, most AMVs rely on radiometric techniques for height assignment that have large uncertainties, particularly for broken or semitransparent clouds and in regions where the temperature lapse rate is small (e.g., polar regions) or inverted (e.g., the marine boundary layer). Relative

\footnotetext{
Corresponding author e-mail: Kevin J. Mueller, kmueller@jpl. nasa.gov
}

to the Cloud-Aerosol Lidar with Orthogonal Polarization (CALIOP), infrared (IR) and visible (VIS) channel AMV heights exhibit mean differences as large as $2.0 \mathrm{~km}$ and standard deviations as large as $3.4 \mathrm{~km}$, depending on the opacity and homogeneity of tracked clouds (Di Michele et al. 2013). Comparison of AMV-assigned heights with height of best fit with model demonstrates AMV-model height differences that are consistent with the lidar results (Salonen et al. 2015), and comparison of AMV heights with the height of best agreement with rawinsonde profiles suggests that height assignment errors represent $70 \%$ of AMV uncertainty (Velden and Bedka 2009). Characterization and reduction of height assignment error continues to be aggressively investigated by the NWP community.

The Multiangle Imaging SpectroRadiometer (MISR) instrument onboard the polar-orbiting Terra satellite retrieves cloud motion vectors (CMVs) whose heights 
are determined by a stereoscopic, rather than radiometric, technique. MISR CMVs and their geometric heights in a $380-\mathrm{km}$ swath are jointly retrieved from red-band $(672 \mathrm{~nm})$ images captured at five of MISR's nine distinct viewing zenith angles including nadir $\left(0^{\circ}\right)$ and $\pm 46^{\circ}$, and $\pm 70^{\circ}$ fore and aft of nadir during a single 7-min overpass by Terra. Little dependence on radiometric calibration is the major advantage of MISRs stereo heights relative to radiometric heights such as those retrieved by Geostationary Operational Environmental Satellite (GOES) and Moderate Resolution Imaging Spectroradiometer (MODIS) AMV algorithms (e.g., Muller et al. 2002; Naud et al. 2005; Garay et al. 2008; Lonitz and Horváth 2011). The publicly available CMVs are reported at $17.6-\mathrm{km}$ resolution (Mueller et al. 2013), with a nearly continuous global record of daylight CMVs dating back to early 2000, and expected to continue until at least 2020. The precision of CMVs has been diagnosed as $180 \mathrm{~m}$ for heights, $1.8 \mathrm{~m} \mathrm{~s}^{-1}$ for northward motion, and $1.1 \mathrm{~m} \mathrm{~s}^{-1}$ for eastward motion (Horváth 2013). Preliminary studies have shown that assimilated MISR CMVs provide a weather forecast benefit (Baker et al. 2014; Cress 2014; Liu and Mueller 2014; Yamashita 2014). In September 2014, MISR CMV products became available in near-real time (NRT) with less than a 2.5-h latency from time of observation.

MISR CMVs have several unique attributes relative to the AMVs regularly assimilated by NWP centers. These include geometric height assignment independent of the atmospheric temperature structure, favorable spatial and temporal resolution, complementary coverage, and comparable horizontal motion accuracy. Routinely assimilated AMVs predominantly consist of data from geostationary-Earth-orbiting (GEO) and polar-orbiting [i.e., low-Earth orbiting (LEO)] satellite instruments that retrieve winds by tracking cloud or water vapor feature movement through sequential VIS, IR, or water vapor (WV) channel imagery, exemplified by GOES and MODIS. More recently, AMVs produced from composite LEO-GEO imagery (e.g., Lazzara et al. 2014) and from constellations of LEO instruments (e.g., Borde et al. 2016) have been added to mitigate coverage gaps between LEO- and GEO-derived AMVs, including the $55^{\circ}-65^{\circ}$ north and south latitude range. CMV coverage is nearly global with a seasonally varying sunlit poleward limit between $65^{\circ}$ and $85^{\circ}$ latitude that overlaps the above instruments and further helps mitigate the coverage gap. Frequent sampling at heights below $70 \mathrm{kPa}$ (i.e., with altitude-equivalent pressure $>70 \mathrm{kPa}$ ) has also been identified as a key complementary strength of CMVs for the purpose of improving forecast accuracy in NWP models (Baker et al. 2014). This strength is, in part, a consequence of distrust in the heights assigned to traditional low-level AMVs, especially in the Arctic, where
MODIS AMVs are deemed unreliable (Key et al. 2003; Santek 2010) and excluded from operational assimilation by multiple NWP centers (Salonen et al. 2015). Low-level AMVs are principally assigned heights by variations of the infrared window (WIN) technique that finds the height of the observed IR brightness temperature within an a priori model profile. This technique has problematic sensitivity to temperature inversions and semitransparent or broken clouds even when corrections are employed to address these challenges (Nieman et al. 1993, 1997).

The 275-m pixel resolution and 3.5-min image sampling (between nadir and fore/aft image triplets) allow MISR to track clouds with fine spatiotemporal variability. The image sampling and $17.6-\mathrm{km}$ resolution of reported CMVs is analogous to the mesoscale GOES AMVs retrieved using the 5-min (rapid scan) image interval identified as optimal (Bedka et al. 2009; Velden et al. 2005). This interval is shorter than the 15-30-min interval used to produce operational GOES AMVs and the 100-min image interval employed for MODIS AMVs. Finer spatiotemporal resolution facilitates capturing details of mesoscale flows, especially anomalous flow patterns that could be beneficial for forecasting weather disturbances (Bedka and Mecikalski 2005; Bedka et al. 2009; Jewett and Mecikalski 2010).

Other MISR CMV products have been studied extensively, including the coarser-resolution $(70.4 \mathrm{~km}) \mathrm{CMVs}$ (Davies et al. 2007; Marchand et al. 2007; Hinkelman et al. 2009; Lonitz and Horváth 2011) and finer-resolution $(1.1 \mathrm{~km})$ cloud heights (e.g., Naud et al. 2002, 2004, 2005). Horváth (2013) compared the latest 17.6-km CMVs with the early 70.4-km product and with collocated Meteosat-9 AMVs for 2008 and found the latest CMVs to improve sampling by $40 \%$ at low atmospheric levels and by a factor of 2-3 at higher levels. More important, the latest CMVs show lessened along-track bias (by $3 \mathrm{~m} \mathrm{~s}^{-1}$ for high clouds) and root-mean-square (RMS) differences relative to Meteosat-9. The goal of the current study is to further characterize CMV sampling and error characteristics of the 17.6-km CMVs by comparing them with other AMVs. The time frame of evaluation is from 2003 to 2008, and the domain includes the eastern Pacific and Americas for comparisons with GOES AMVs and the Arctic/Antarctic for comparisons with MODIS AMVs.

\section{Data and methods}

\section{a. Data}

The MISR 17.6-km CMVs used in this study were obtained from the level $3 \mathrm{CMV}$ product version F02_0002, which is publicly available at the NASA Langley Atmospheric Science Data Center (ASDC) 
TABLE 1. Sensitivity of MISR CMV retrieval to along-track error in image coordinates of tracked features, adapted from Davies et al. (2007). Note that $x_{\mathrm{Df}}$ and $x_{\mathrm{Bf}}$ refer to SOM $x$ coordinates within Bf and Df camera images.

\begin{tabular}{|c|c|c|c|c|}
\hline $\begin{array}{l}\text { Image pixel } \\
\text { coordinate error }\end{array}$ & $\begin{array}{l}\text { Height } \\
\text { error }(\mathrm{m})\end{array}$ & $\begin{array}{l}\text { Along-track } \\
\text { error }\left(\mathrm{m} \mathrm{s}^{-1}\right)\end{array}$ & 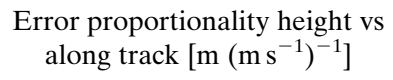 & $\begin{array}{l}\text { Error proportionality along track vs } \\
\text { height error }\left(\mathrm{m} \mathrm{s}^{-1} \mathrm{~km}^{-1}\right)\end{array}$ \\
\hline $275 \mathrm{~m}$ in $x_{\mathrm{Df}}$ & 519 & -5.6 & 93 & 11 \\
\hline $275 \mathrm{~m}$ in $x_{\mathrm{Bf}}$ & -1159 & 15.5 & 75 & 13 \\
\hline
\end{tabular}

(https://eosweb.larc.nasa.gov/news/misr-level-3-cloudmotion-vector). The near-real-time corollary of the above is the level 2 NRT CMV product, for which $95 \%$ of CMVs are available within $2.5 \mathrm{~h}$ of the satellite overpass. Both the operational and NRT CMV products employ the same retrieval algorithm and are functionally equivalent, though they are not identical on a per-retrieval basis. Because of differences in the upstream data inputs, particularly those that influence camera registration, there is a random vector root-mean-square (VRMS) difference of $3 \mathrm{~m} \mathrm{~s}^{-1}$ in collocated cloud motion reported in the two products (Mueller et al. 2014).

Height-assigned CMVs are obtained from a single Terra satellite overpass by tracking feature progression within MISR red-band imagery over the 3.5-min interval between the initial $70^{\circ}$ forward view and the nadir $\left(0^{\circ}\right)$ view and then again for the same interval between the nadir view and the final $70^{\circ}$ aft view (Horváth and Davies 2001; Mueller et al. 2013). In addition to the nadir and $70^{\circ}$ views, an intermediate view angle of $45.6^{\circ}$ is used to distinguish between stereoscopic parallax and the component of cloud motion along the ground track of Terra. Features are tracked by a hierarchical pattern matching algorithm first applied to $7 \times 7$ groups of 1.1-km resolution pixels and finally applied to $25 \times 25$ groups of 275 -m pixels. The height and motion of features tracked independently by the forward and aft camera triplets are averaged in the retrieval with a quality indicator (QI) assigned on the basis of fore-aft difference and spatial coherency relative to retrievals in adjacent cells (Mueller et al. 2013).

Because of the need to distinguish parallax from motion, tracking and georegistration errors influence the accuracy of MISR-retrieved motion in the along-track direction to a greater extent than the cross-track direction and introduce a correlation between the errors in retrieved cloud height and along-track cloud motion (Horváth and Davies 2001; Zong et al. 2002). Davies et al. (2007) modeled CMV sensitivity to error in each camera's tracked feature coordinates, expressing their results relative to a $275-\mathrm{m}$ (i.e., one pixel) error in the space oblique Mercator (SOM) $x$-coordinate axis, which is aligned with the Terra ground track to within $10^{\circ}$. These results (summarized in Table 1) show that the retrieved height error is proportional to the along-track motion

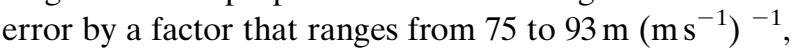

depending on the relative contributions associated with each camera. Statistics of the differences between the independent for and aft set of retrievals made for the same $17.6-\mathrm{km}$ region can be used to further quantify the contributions of tracking and georegistration errors. The global RMS of fore-aft differences for CMVs assigned QI $\geq 50$ from 2003 to 2008 is $3.1 \mathrm{~m} \mathrm{~s}^{-1}$ along track, $1.2 \mathrm{~m} \mathrm{~s}^{-1}$ cross track, and $250 \mathrm{~m}$ for the assigned height.

GOES AMVs used in this study were obtained from the National Oceanic and Atmospheric Administration (NOAA) National Environmental Satellite, Data, and Information Service (NESDIS) following a reprocessing undertaken by the Space Science and Engineering Center (SSEC) at the University of Wisconsin-Madison using the current operational software (Wanzong et al. 2014) (http://tropic.ssec.wisc.edu/archive/data/goes_reprocess/ wind_files). The software tracks cloud or water vapor features across three-image sequences in the VIS, shortwave infrared (SWIR), IR, and WV channels (Nieman et al. 1997). The GOES VIS and IR channels investigated in this study have respective resolutions of 1 and $4 \mathrm{~km}$ at nadir. The AMV algorithm, which is planned to be replaced soon by a nested tracking approach, is tailored to track patterns within $15 \times 15$ pixel patches, representing areas of 225 (VIS) and $3600 \mathrm{~km}^{2}$ (IR) (Bedka et al. 2009). Heights are assigned by one of three methods: $\mathrm{CO}_{2}$ slicing, $\mathrm{H}_{2} \mathrm{O}$ intercept, or WIN/histogram (Nieman et al. 1993). The WIN technique infers the cloud brightness temperature from the measured IR radiance and then uses an a priori temperature profile to map from temperature to pressure level. Selectively employed variations of the WIN technique use the warmest temperature associated with an observed clustering of cloudy pixels (BASE) or apply a pressure correction to account for temperature inversions (WINV). Assigned heights may be further adjusted during postprocessing to establish consistency with adjacent winds and a forecast model background (Velden and Bedka 2009). Different quality metrics are available for each AMV. This study employs the quality indicator no forecast (QINF) metric that assesses only spatiotemporal coherency with adjacent winds as opposed to an alternate metric incorporating comparison with forecast winds (Velden et al. 1998). This provides a more direct comparison with MISR CMV retrievals, whose QI includes no forecast model comparison. 
Only AMVs with QINF > 60 are investigated here, as in Bedka et al. (2009). Comparisons of GOES AMVs with the NOAA network of ground-based Doppler wind profilers showed a VRMS difference of $5.6 \mathrm{~m} \mathrm{~s}^{-1}$ from April 2005 to April 2006 (Bedka et al. 2009). VRMS varied little with wind height, peaking at $5.9 \mathrm{~m} \mathrm{~s}^{-1}$ for winds at heights below $70 \mathrm{kPa}$.

The reprocessed GOES AMVs used in this study are organized by the four regions regularly observed by the GOES-East and GOES-West satellites: east-Southern Hemisphere (E-SH), east-Northern Hemisphere (E-NH), west-Southern Hemisphere (W-SH), and west-Northern Hemisphere (W-NH). During the 2003-08 period of this study, AMVs are typically available on a 3-hourly basis, having been produced from triplets of images separated by intervals ranging from 15 to $30 \mathrm{~min}$, with precedence given to shorter intervals. The interval is governed by the availability of data, which is set by the schedule of instrument observation targets and modes (see Wanzong et al. 2014). The GOES AMVs are guided by a priori temperature and wind profiles interpolated from the 6-hourly analysis state of the European Centre for Medium-Range Weather Forecasts (ECMWF) ERA-Interim model.

The MODIS AMVs used in this study were obtained from the Cooperative Institute for Meteorological Satellite Studies (CIMSS), which maintains an archive of operationally derived wind observations (ftp://stratus.ssec. wisc.edu/pub/winds/archive/modis/terra). MODIS AMVs are produced at latitudes poleward of $55^{\circ}$ from image triplets sampled over consecutive orbits from multiple instruments, including MODIS-Terra and MODIS-Aqua (Key et al. 2003; Velden et al. 2005). The necessity of using consecutive orbits enforces a fixed 100-min time interval between images used in feature tracking when employing a single MODIS instrument. Utilizing both MODIS-Terra and MODIS-Aqua allows opportunistic retrievals from the overlap of images separated by shorter intervals. This study focuses on AMVs derived only from MODIS-Terra using the IR window band at $11 \mu \mathrm{m}$. The retrieval algorithm, modeled after that used with GOES imagery, tracks $13 \times 13$ pixel patterns in reprojected imagery representing a $26 \mathrm{~km} \times 26 \mathrm{~km}\left(676 \mathrm{~km}^{2}\right)$ area. Operational MODIS AMVs are guided by a priori temperature and wind profiles interpolated from the 6- and 9-h forecasts from the NOAA Global Forecast System (GFS) model. Relative to rawinsondes, MODIS AMVs exhibit an overall RMS difference of $8.1 \mathrm{~m} \mathrm{~s}^{-1}$ averaged over all vertical levels, with the largest differences corresponding to low-level AMVs (Key et al. 2003).

\section{b. Methodology}

For this analysis, an algorithm was developed to collocate MISR and GOES motion vectors (and similarly with MODIS) and to compare their sampling statistics (e.g., the probability of retrieval). First, for every GOES observation, the nearest MISR orbit in time was identified, and the SOM coordinates that correspond to the latitude and longitude of the GOES retrieval were determined. These coordinates were then translated into $17.6 \mathrm{~km} \times 17.6 \mathrm{~km}$ resolution grid cell indices. Motion vectors from MISR and GOES with the same indices were considered collocated in space. Spatially collocated motion vectors with a time separation greater than 30 min were excluded.

Height-equivalent pressure levels and collocated model reanalysis winds for CMVs were obtained from geopotential height $(\mathrm{GPH})$ versus pressure profiles obtained from Modern-Era Retrospective Analysis for Research and Applications (MERRA) data (Rienecker et al. 2011). Pressure-equivalent heights and winds were obtained in a similar manner for the GOES AMVs. The specific MERRA dataset used is designated MAI3CPASM.5.2.0, which provides model state variables every three hours on a uniform $0.25^{\circ} \times 0.25^{\circ}$ latitudelongitude grid with vertical pressure levels specified every $2.5 \mathrm{kPa}$ at low levels. Each AMV or CMV was assigned a nearest-neighbor MERRA horizontal grid cell, and coefficients for interpolating vertical grid coordinates were determined from lower- and upperbounding GPHs provided by MERRA. This procedure disqualified from comparison a number of CMVs at heights below the lowest GPH. Throughout this study, comparisons of geometric heights were undertaken relative to geoid-referenced heights rather than the World Geodetic System 1984 (WGS84) ellipsoid-referenced heights reported in the MISR CMV product. The WGS84 Earth Gravitational Model (EGM84) geoid model was used to translate between the two.

For each orbit and each GOES image quadrant (i.e., E-SH, E-NH, W-SH, W-NH), a set of spatially collocated observations were obtained using the above approach. A total of 4.8 million GOES VIS channel and 1.1 million GOES IR channel collocations with MISR were identified. CMVs and MODIS AMVs were collocated by similar methodology, though only MODIS-Terra IR channel AMVs were included. A total of 2.7 million such collocations were obtained.

Equivalent sampling domains for CMVs and for GOES AMVs were derived by identifying, for each GOES image quadrant, the set of MISR orbits during which that quadrant produced at least one CMV and AMV. Then, for each quadrant and orbit, only those CMVs and AMVs within the spatial extent visible to both instruments during that MISR orbit were accumulated. Extents were defined in SOM coordinate space, which consists of a map projection for each unique orbit path within the Terra 
TABLE 2. Collocations of MISR CMV retrievals with GOES AMV retrievals constrained with respect to the SOM coordinate system to a subset firmly within the interior of each instrument's observational swath. The SOM boundaries are defined below.

\begin{tabular}{lccc}
\hline \hline Retrieval domain & SOM paths & SOM blocks & $y$-grid indices \\
\hline MISR & & $1-20$ & $12-20$ \\
& & $21-40$ & $9-22$ \\
& & $41-140$ & $6-25$ \\
& & $141-160$ & $9-22$ \\
GOES E-NH & $213-219$ & $161-180$ & $12-20$ \\
& $220-233$ & $58-89$ & \\
GOES W-NH & $1-29$ & $51-89$ & \\
GOES E-SH & $220-75$ & $51-89$ & \\
& $1-233$ & $91-126$ & \\
GOES W-SH & $37-68$ & $91-126$ & \\
\hline
\end{tabular}

repeat cycle, within which the $x$ axis is aligned with the satellite ground track, and the instrument swath is fixed relative to the $y$ axis (Jovanovic et al. 2012). For MISR, bounds representing the interior of the MISR swath were defined relative to block-specific ranges of $y$ coordinates. For GOES, sets of SOM paths and path-specific block ranges define the interior of the GOES retrieval domain for each GOES image region. Specific bounds are provided in Table 2. The total number of CMV samples found using this approach was 41.7 million, whereas the comparable numbers of GOES IR and VIS AMV samples were 5.5 and 1.9 million, respectively. The denser sampling of motion vectors provided by MISR is only partially attributable to the finer resolution of the MISR product. To demonstrate this, the above MISR, GOES VIS channel, and GOES IR channel motion vectors were regridded into $2.5^{\circ}$ latitude $\times 2.5^{\circ}$ longitude bins. The number of MISR orbits for which each bin was sampled one or more times was counted for each retrieval. Figure 1 maps the results, demonstrating the tendency of MISR to produce a greater number of successful retrievals during each Terra overpass. Particularly over land, CMV sampling is more consistent.

\section{Results and discussion}

In the following sections, heights and wind component differences as a function of height for horizontally and temporally collocated MISR CMVs and GOES AMVs are compared (section 3a), and along-track differences with respect to height for these collocations are reviewed (section 3b). Similar analyses for collocated MISR CMVs and MODIS AMVs are presented in sections $3 c$ and $3 d$. Sampling and difference distributions for the subset of above collocations where pairs of retrievals agree in height are reviewed in sections $3 \mathrm{e}$ and $3 f$, respectively. Statistical summaries for these subsets are discussed in section $3 \mathrm{~g}$.

\section{a. Height comparisons of MISR CMVs collocated with GOES AMVs}

Systematic errors in MISR CMV and GOES AMV heights are diagnosed by identifying scenarios where the retrievals report similar winds at different heights. This is done by evaluating mean differences in retrieved motion as a function of collocated and paired AMV and CMV heights. Height comparison histograms were constructed by assigning each CMV height to one of 16 vertical bins, each $250 \mathrm{~m}$, ranging from -1 to $3 \mathrm{~km}$, or to

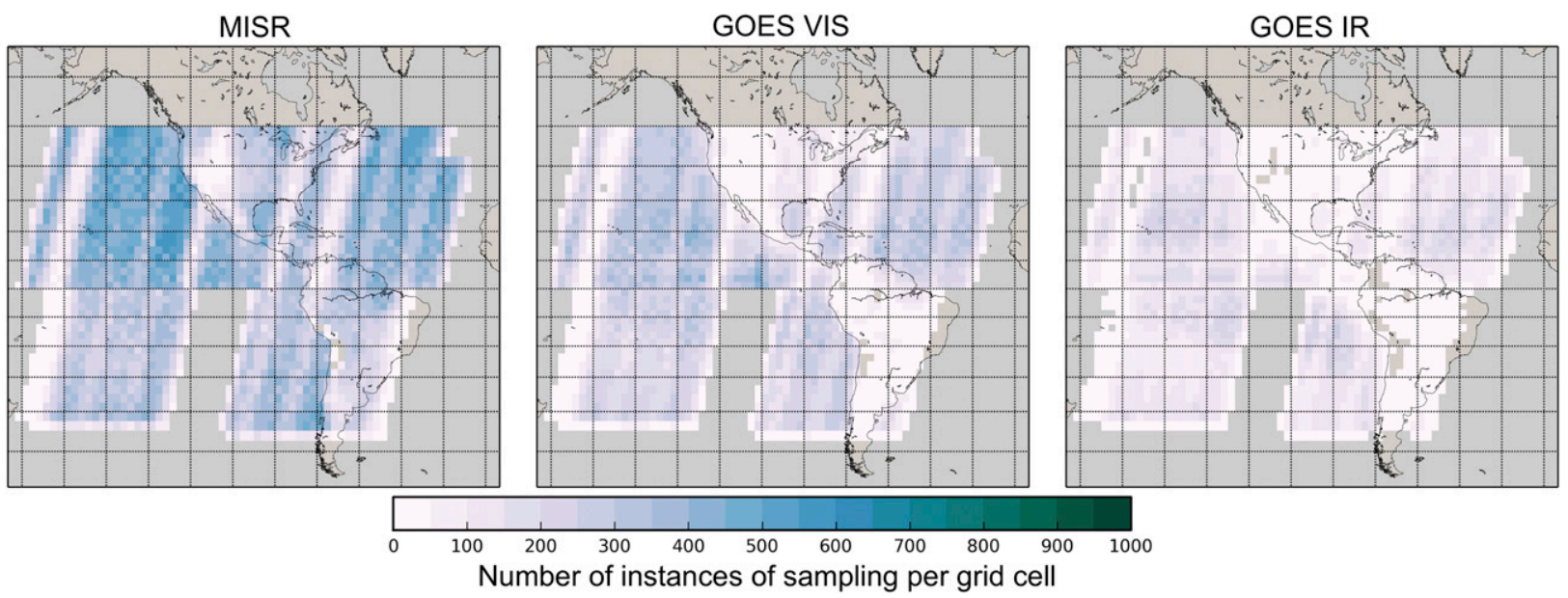

FIG. 1. Comparison of low-level (pressure level $>40 \mathrm{kPa}$ ) motion vector sampling between (left) MISR, (center) GOES VIS channel, and (right) GOES IR channel. The sampling domain in each is limited to motion vectors within view of MISR during a specific orbit and within 30 min of a GOES scan. 

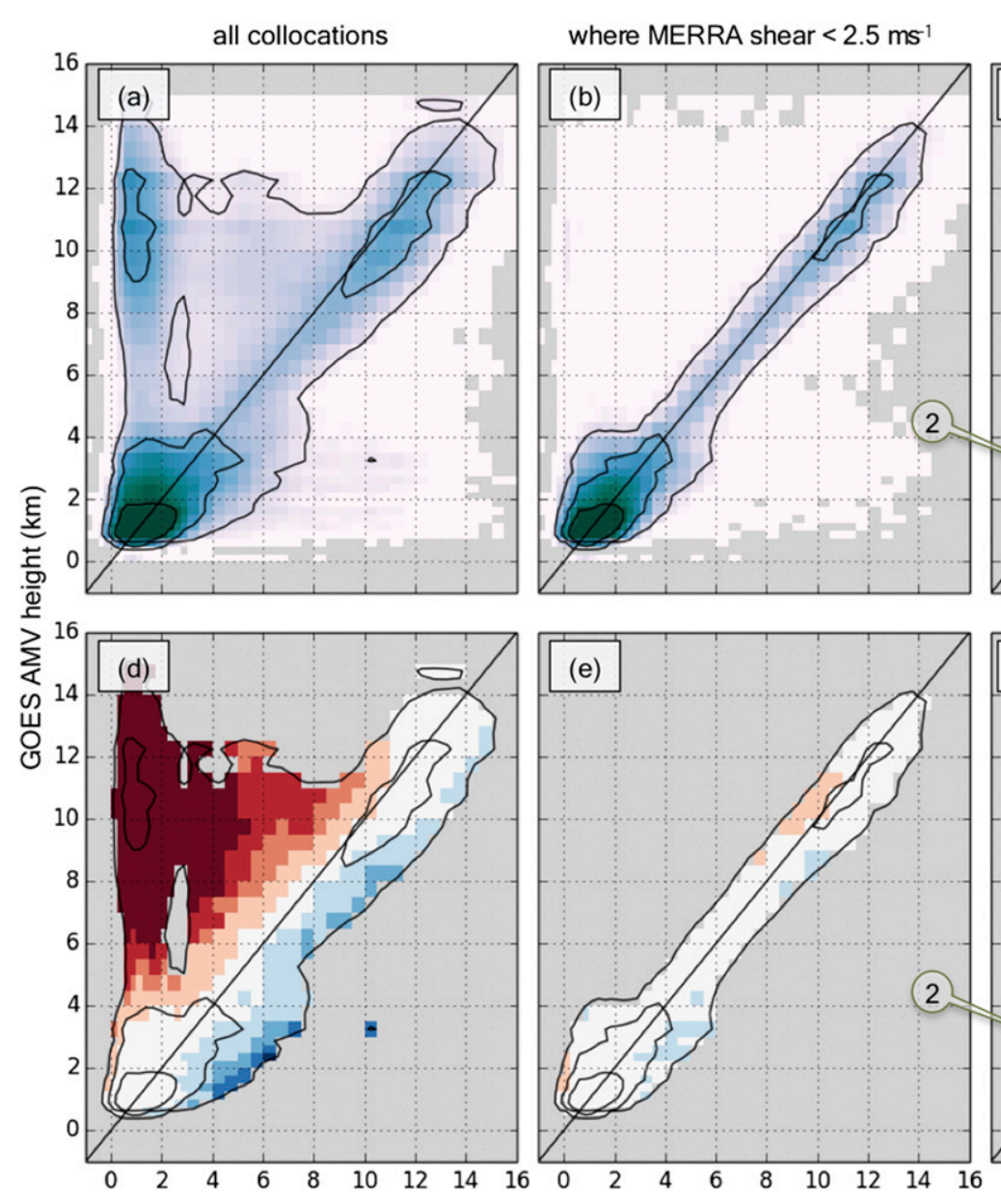

where MERRA shear $\geq 2.5 \mathrm{~ms}^{-1}$

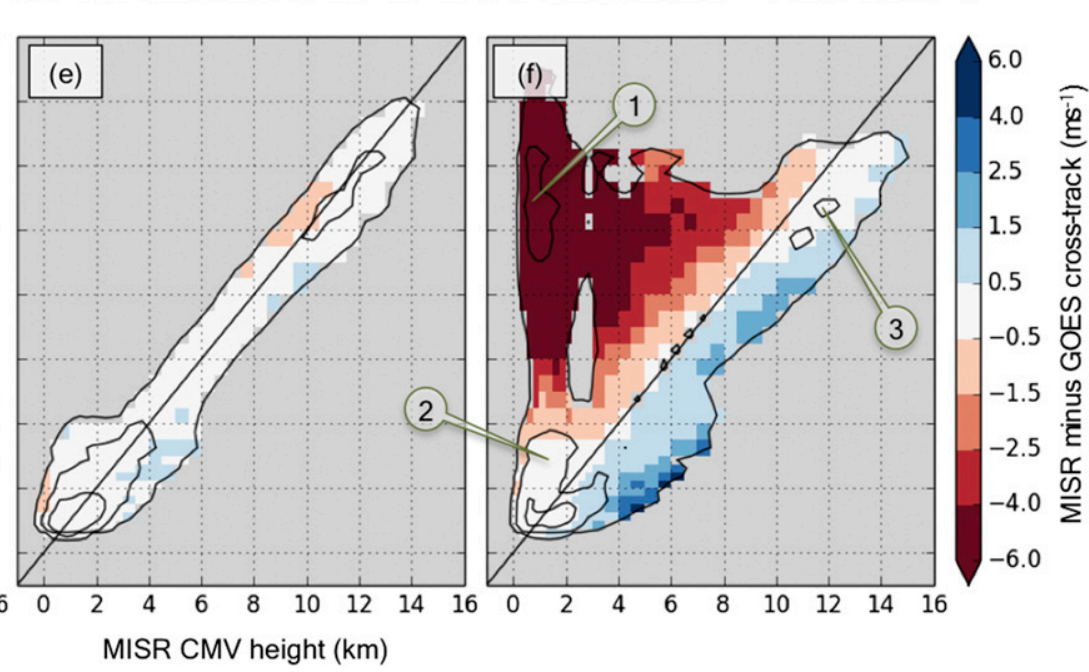

FIG. 2. Joint distribution of MISR stereo height and GOES pressure-equivalent height for collocations of MISR CMVs with GOES IR and VIS channel AMVs. The number of samples $N$ per height bin is shown for (a) all paired collocations, (b) those pairs where MERRA reanalysis indicates wind shear between MISR and GOES reported heights $<2.5 \mathrm{~m} \mathrm{~s}^{-1}$, and (c) those with wind $\geq 2.5 \mathrm{~m} \mathrm{~s}^{-1}$. (d) $-(\mathrm{f}) \mathrm{Mean}$ differences between MISR and GOES for the cross-track component of collocated motion vectors assigned to each bin. Contours for $N=200,2000$, and 20000 are drawn.

one of 26 vertical bins, each $500 \mathrm{~m}$, ranging from 3 to $16 \mathrm{~km}$. Each collocated GOES pressure-equivalent height was then assigned to a corresponding set of bins to facilitate comparison. Finally, two subcategories of histograms were generated on the basis of whether or not the wind shear associated with each difference in height exceeds $2.5 \mathrm{~m} \mathrm{~s}^{-1}$ in the MERRA reanalysis. Estimates of wind shear compared MERRA winds that had been separately matched with each MISR and GOES retrieval, implicitly introducing sensitivity to time and location differences between collocated pairs of CMVs and AMVs.

Sampling density for paired heights of MISR CMV and GOES AMV does not tightly cluster along the 1:1 line in Fig. 2a, suggesting that the CMV and AMV heights are not strongly correlated. Only where both have heights above about $8 \mathrm{~km}$ is a strong correlation apparent. Nevertheless, $73 \%$ of MISR-GOES collocations are at sufficiently similar heights so as to be insensitive to vertical wind shear, as shown in Fig. 2b. The remainder are shown in Fig. 2c. In Fig. 2c, there is a cluster of points, labeled (1), for which CMVs reported at heights from 0 to $2 \mathrm{~km}$ are paired with GOES AMVs with heights ranging from 6 to $16 \mathrm{~km}$. This cluster represents multilayer scenes where the CMV retrieval tracked low-level clouds while the AMV algorithm tracked upper-level clouds. This phenomenon, which is typically due to differences between VIS and IR imagery, has been visually verified and discussed in greater detail relative to MISR CMVs and Meteosat AMVs by Lonitz and Horváth (2011). These tracking mismatches in multilayer scenes make up nearly all of 


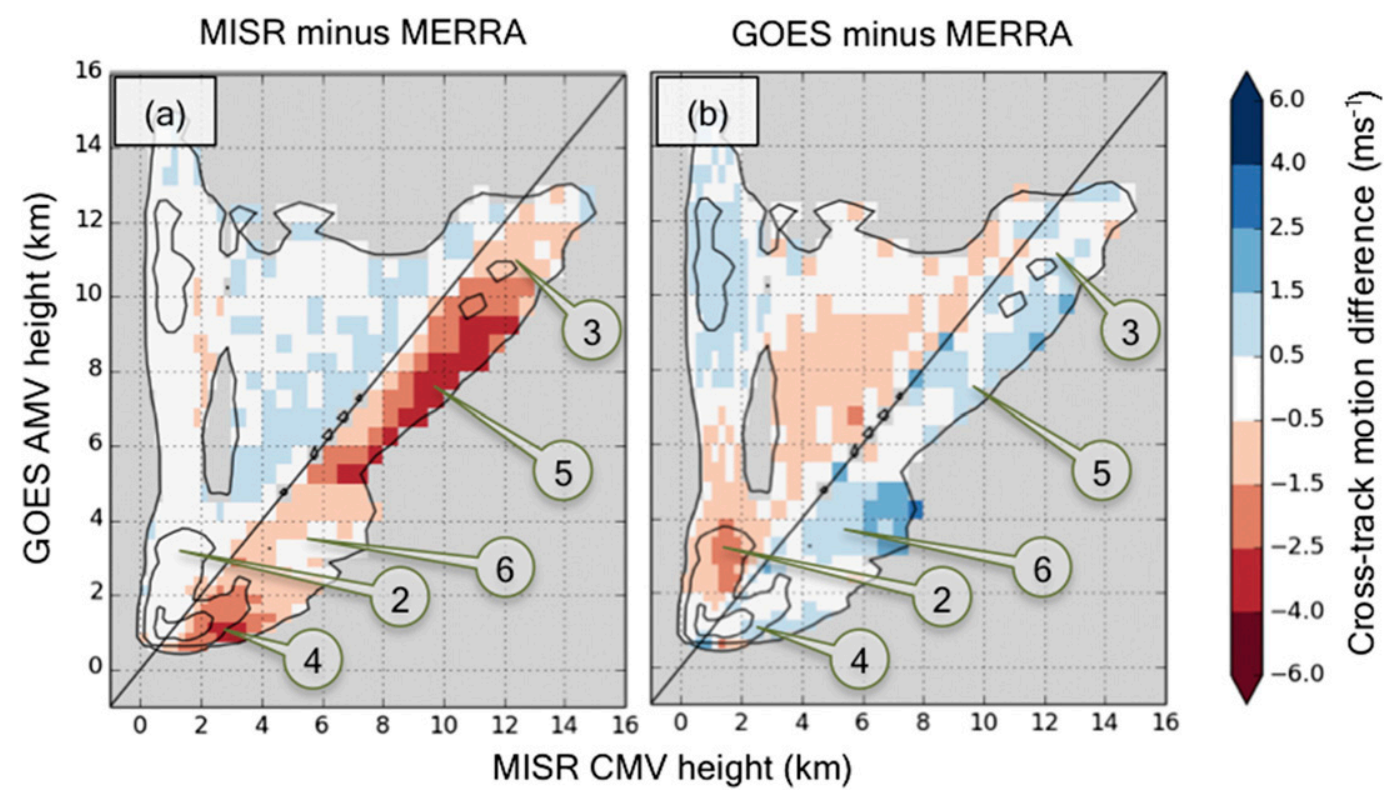

FIG. 3. As in Fig. 2f, but for the mean difference of (a) MISR CMVs or (b) GOES AMVs cross-track motion components with respect to coincident MERRA reanalysis winds.

the height comparison bins in the upper-left quadrant of Fig. 2c.

As shown in Fig. 2e, collocated pairs of CMVs and AMVs that have tracked features at similar heights, such that wind shear is minimal, exhibit systematic differences in cross-track motion relative to height that are consistently less than $0.5 \mathrm{~m} \mathrm{~s}^{-1}$. This strong agreement enables cross-track differences to serve as a diagnostic for whether height differences are due to tracking mismatches or errors in the heights reported by CMV and/or AMV. Tracking mismatches are identifiable as mean cross-track motion differences greater than $0.5 \mathrm{~m} \mathrm{~s}^{-1}$, as is the case for cluster (1) in Fig. 2f. In contrast, there is a cluster of GOES AMVs labeled (2), representing 37\% of GOES AMVs with reported heights from 2 to $4 \mathrm{~km}$, which are as much as $3 \mathrm{~km}$ higher than their CMV counterparts. Although MERRA indicates differences in height should produce significant shear, no systematic differences in retrieved cross-track motion are present among cluster (2). To examine this further, Fig. 3 individually compares height-binned GOES AMV and MISR CMV cross-track components with coincident MERRA reanalysis winds. In this figure, cluster (2), which corresponds to the same cluster in Fig. 2f, indicates that the MERRA winds at the lower, MISRreported heights are in better agreement with the satellite retrievals than the winds at the GOES-reported heights - the latter showing a mean motion difference of about $-2 \mathrm{~ms}^{-1}$. This is consistent with the study by Salonen et al. (2015), which showed GOES heights in the range from 60 to $80 \mathrm{kPa}$ are typically $25 \mathrm{kPa}$ above the heights of best agreement with collocated forecast model wind profiles.

Returning to Fig. 2f, there is another cluster, labeled (3), representing $25 \%$ of $\mathrm{CMVs}$, that have assigned heights from 10 to $13 \mathrm{~km}$, for which the retrieved MISR heights are as much as $3 \mathrm{~km}$ above their GOES counterparts. Figure 3 shows that in this cluster, the cross-track components of the GOES AMVs agree better with the MERRA winds than those of the MISR CMVs. Comparison with reanalysis also shows that cluster (3) is consistent with a wider pattern of mean cross-track motion differences with magnitudes $>2.5 \mathrm{~m} \mathrm{~s}^{-1}$, labeled (4) and (5), for which CMVs are assigned to height bins $1-2 \mathrm{~km}$ above the paired GOES AMV heights in the $0-2-\mathrm{km}$ and $5-15-\mathrm{km}$ ranges, respectively. The GOES AMVs in all cases exhibit significantly less mean absolute cross-track differences relative to MERRA, suggesting that the CMV heights in these bins are biased high.

\section{b. Height-dependent MISR CMV along-track wind component biases relative to GOES}

Inherent coupling of error in the MISR CMV retrieval cited in section 2a results in CMV with biased heights and correspondingly biased along-track component of motion. As a result, where MISR error is responsible for height differences between paired MISR and GOES retrievals, along-track differences are expected. Figure 4 repeats the analysis shown in Fig. 2 but for the alongtrack component. For the cases with large wind shear, 

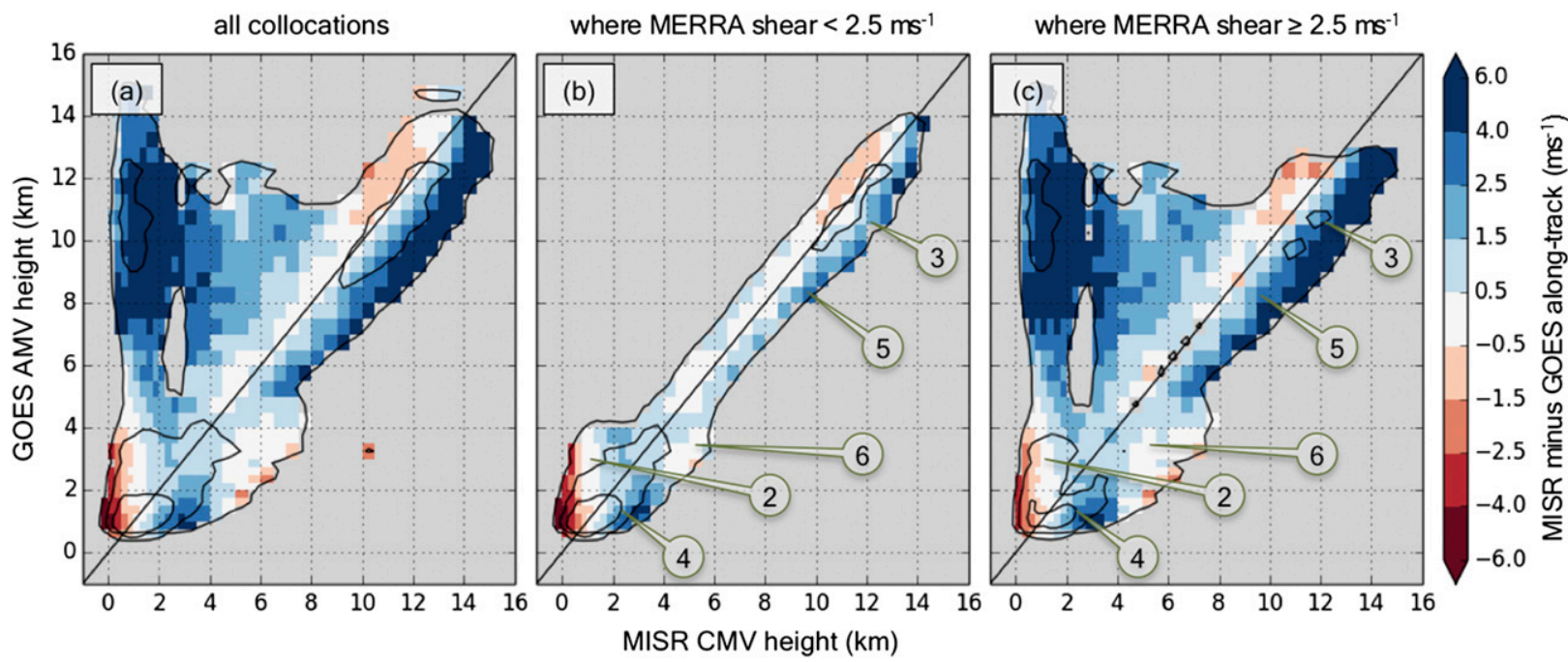

FIG. 4. As in Figs. 2d-f, but for the mean difference between along-track wind components reported by MISR CMVs and GOES AMVs.

Fig. 4c shows that the clusters labeled (3), (4), and (5), previously identified as likely to have MISR height assignments biased high by $1-2 \mathrm{~km}$, also exhibit positive along-track bias relative to GOES. These same clusters are labeled in Fig. 4b, where they also exhibit alongtrack bias, eliminating the possibility that vertical wind shear is responsible. Overall, there is a pattern of CMVs exhibiting positive along-track differences relative to GOES whenever the reported heights are higher than the paired GOES heights. The one prominent exception is a sizable number of midlevel (4-7 km) CMVs, labeled (6) in Figs. 3 and 4, that are as much as $4 \mathrm{~km}$ higher than their GOES counterparts. Smaller absolute mean cross-track (and along track) differences for both MISR and GOES relative to MERRA for these pairs suggest they are tracking mismatches.

The along-track differences plotted in Fig. 4 exhibit gradients consistent with correlated errors in the MISR retrieval of along-track motion and height. For example, in Fig. 4b, along-track differences between the MISR CMVs and GOES AMVs at heights above $10 \mathrm{~km}$, where the MISR height assignment is more than $2 \mathrm{~km}$ above the paired GOES height assignment, marked with label (3), have a diagonal gradient ranging from $-1 \mathrm{~m} \mathrm{~s}^{-1}$ for pairs $500 \mathrm{~m}$ above the $1: 1$ line to $+5 \mathrm{~m} \mathrm{~s}^{-1}$ and greater for pairs below. The orientation of the gradient perpendicular to the 1:1 line is indicative of the correlation between difference in height assignment and difference in the along-track component. Below $4 \mathrm{~km}$, especially at label (2), the alongtrack difference gradient is horizontal instead of diagonal, indicating that correcting for the apparent CMV height and along-track bias would still not produce correlation in height between pairs of collocated CMVs and AMVs.

\section{c. Height comparisons of MISR CMVs collocated with MODIS AMVS}

Height assignments of MISR-MODIS CMVs and AMVs were analyzed in a similar manner as the MISR-GOES collocations (section 3a). The results are presented in Fig. 5. As with the MISR-GOES comparison, Fig. 5e shows that MISR CMVs exhibit no systematic differences relative to paired MODIS AMVs where MERRA indicates vertical wind shear of less than $2.5 \mathrm{~m} \mathrm{~s}^{-1}$ associated with the retrieved heights. However, Figs. 5a and 5c show that MODIS AMV heights have a broad tendency to be $0.5-2.0 \mathrm{~km}$ above their CMV counterparts at low levels (height $<5 \mathrm{~km}$ ), and to be $0.5-2.0 \mathrm{~km}$ below their CMV counterparts at upper levels (height $>5 \mathrm{~km}$ ). This pattern of height bias relative to MISR is the same as that reported by Holz et al. (2008) for polar MODIS cloud-top heights (produced using a similar algorithm as the MODIS AMV heights) relative to CALIOP lidar heights. At low levels, it is also consistent with the bias inferred from a comparison with forecast model winds (Salonen et al. 2015).

Comparison of Figs. 2f and $5 \mathrm{f}$ shows that MISR CMV heights differ from collocated MODIS AMV heights more often than is the case for MISR and GOES, such that only $60 \%$ of the MISR-MODIS collocations appear insensitive to vertical wind shear. Some of these height differences are readily evident as tracking mismatches, such as the collocations labeled (7) in Fig. 5f, where CMVs are assigned to the $0-2-\mathrm{km}$ 


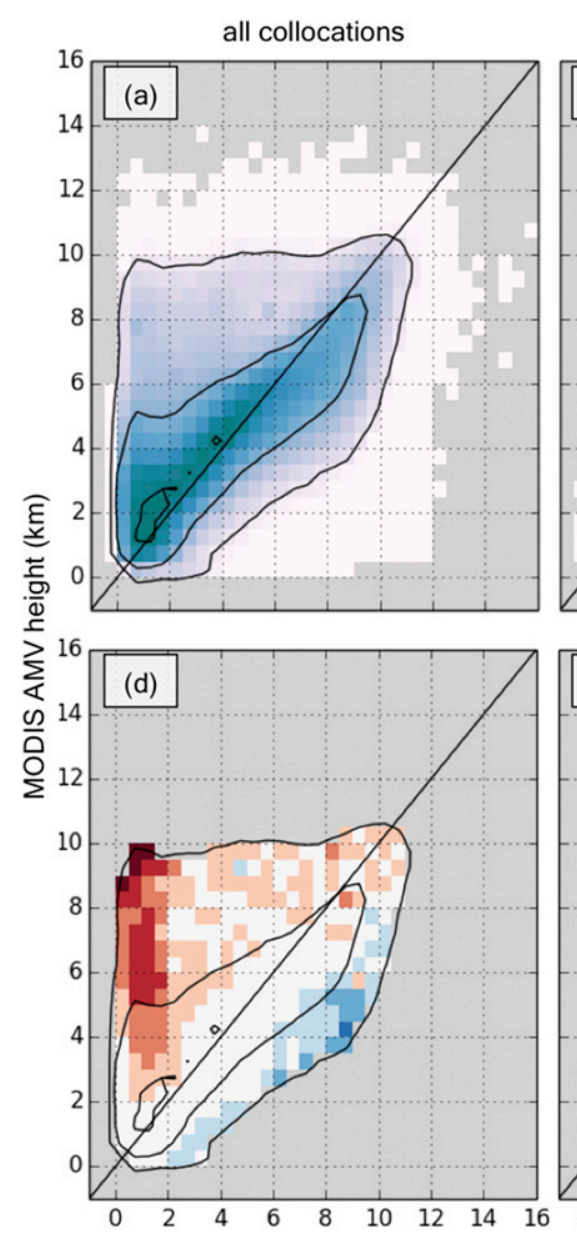

where MERRA shear $<2.5 \mathrm{~ms}^{-1}$
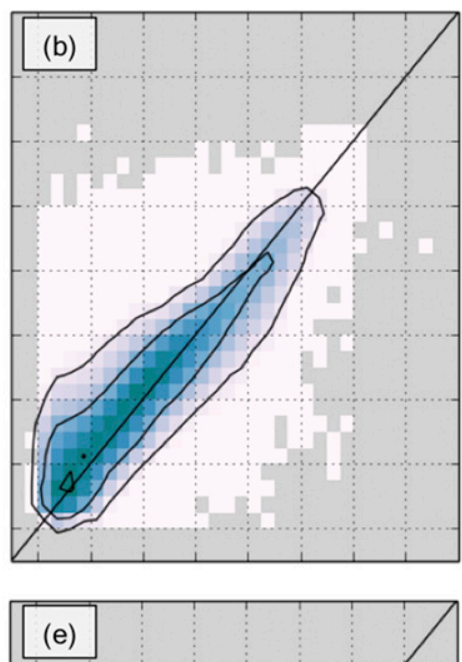

\section{(e)}

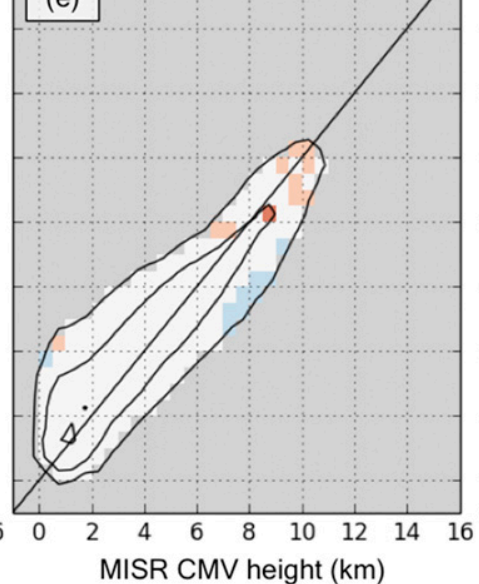

where MERRA shear $\geq 2.5 \mathrm{~ms}^{-1}$

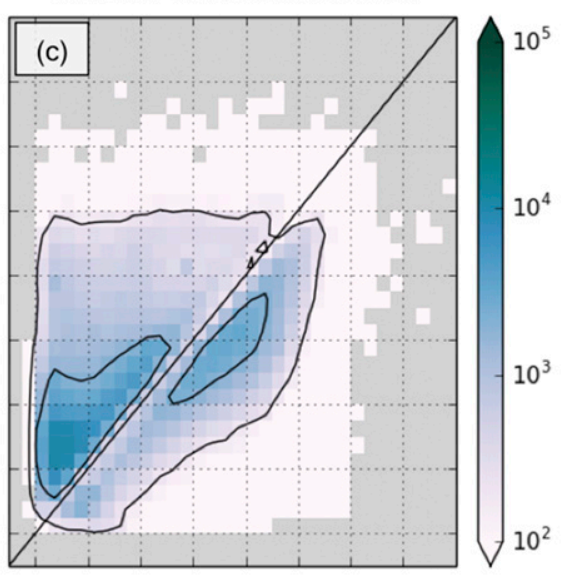

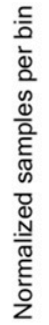

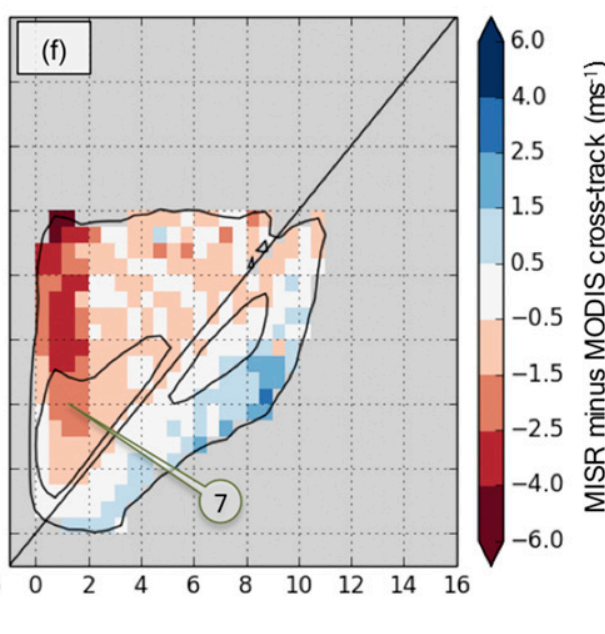

FIG. 5. As in Fig. 2, but comparing MISR CMVs with MODIS IR channel AMVs.

height range and MODIS AMVs are assigned to $2-10 \mathrm{~km}$. Cross-track motion differences range from 2 to $4 \mathrm{~m} \mathrm{~s}^{-1}$. The overall pattern of cross-track differences between MISR and MODIS in Fig. 5f, including (7), is nearly equivalent to the pattern resulting from differences in retrieved wind height expected from reanalysis (not shown), suggesting that tracking mismatches are responsible for the observed cross-track differences. This is a consequence of substantial differences between the MISR CMV and MODIS AMV retrievals, not the least of which is the lack of a VIS channel in deriving the MODIS AMVs. Clouds tracked during a MISR 7-min overpass may become obscured or dissipate during the 100-min interval between MODIS-Terra image pairs. There are also significant differences in the cloud regimes observed by MODIS and GOES when collocated with MISR. The multilayer polar stratus predominately observed in the MISR-MODIS collocations are far more prone to producing tracking mismatches than the stratocumulus clouds that dominate the MISR-GOES collocations (Klein and Hartmann 1993).

\section{d. Height-dependent MISR CMV along-track wind component biases relative to MODIS}

Figure 6 shows that MISR CMVs exhibit predominantly positive along-track bias relative to MODIS AMVs at all heights and regardless of the presence of wind shear. Where MERRA indicates shear less than $2.5 \mathrm{~m} \mathrm{~s}^{-1}$, the magnitude of that bias is $1-2 \mathrm{~m} \mathrm{~s}^{-1}$ at CMV heights below $6 \mathrm{~km}$, with a pattern of larger along-track differences away from the 1:1 line where CMV and AMV heights differ more. Above $6 \mathrm{~km}$, the bias increases to $4 \mathrm{~m} \mathrm{~s}^{-1}$. In the presence of wind shear, a gradient of along-track differences relative to height is evident in Fig. 6c. That gradient is a product of the mean wind shear indicated by MERRA between paired heights of CMVs and AMVs. Indeed, its sign is 

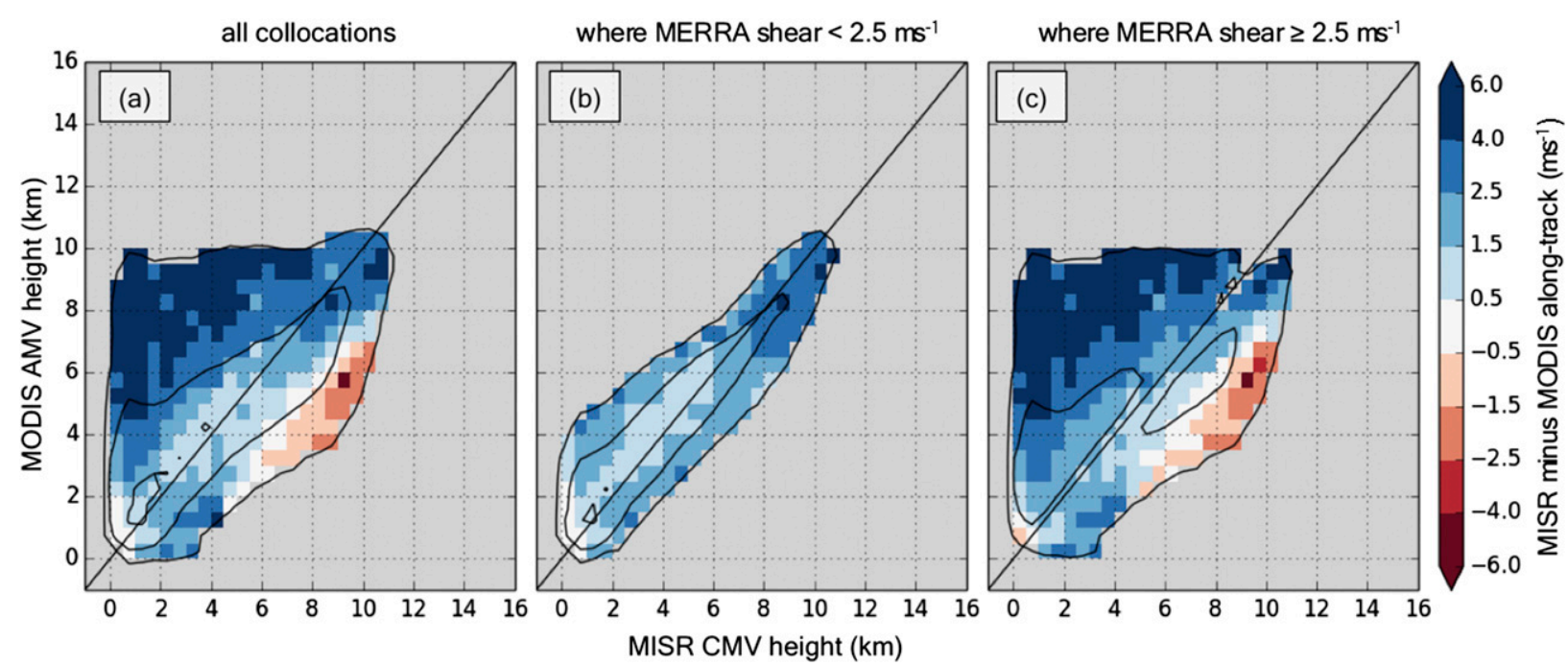

FIG. 6. As in Figs. 5d-f, but for the mean difference between along-track wind components reported by MISR CMVs and MODIS AMVs.

opposite that of the gradients observed in Fig. 4 that were caused by correlated error in the CMV retrieval, further underscoring the fact that apparent differences between MISR CMVs and MODIS AMVs are driven by tracking mismatches in multilayer scenes.

\section{e. Geographic distribution of collocations between MISR CMVs and GOES and MODIS AMVS}

Previous sections demonstrated the role of tracking mismatches in governing apparent differences between collocated MISR CMVs and MODIS and GOES AMVs. To diminish this role, differences are now assessed for collocated pairs from which height differences greater than $1.5 \mathrm{~km}$ have been excluded.
Figures $2 \mathrm{a}$ and $5 \mathrm{a}$ showed sampling for all collocations as a function of height (and height difference), providing context for this exclusion. Additional screening is introduced to remove pairs with large magnitude $\left(>10 \mathrm{~m} \mathrm{~s}^{-1}\right)$ along-track wind component differences (LMATDs) between the CMV and AMV. Although LMATDs represent less than $5 \%$ of paired collocations, they are excluded because their frequency is anomalously large relative to what would otherwise be a Gaussian distribution of along-track differences.

The MISR-GOES map in Fig. 7b shows that the majority of samples come from marine stratocumulus regions off the west coast of North and South
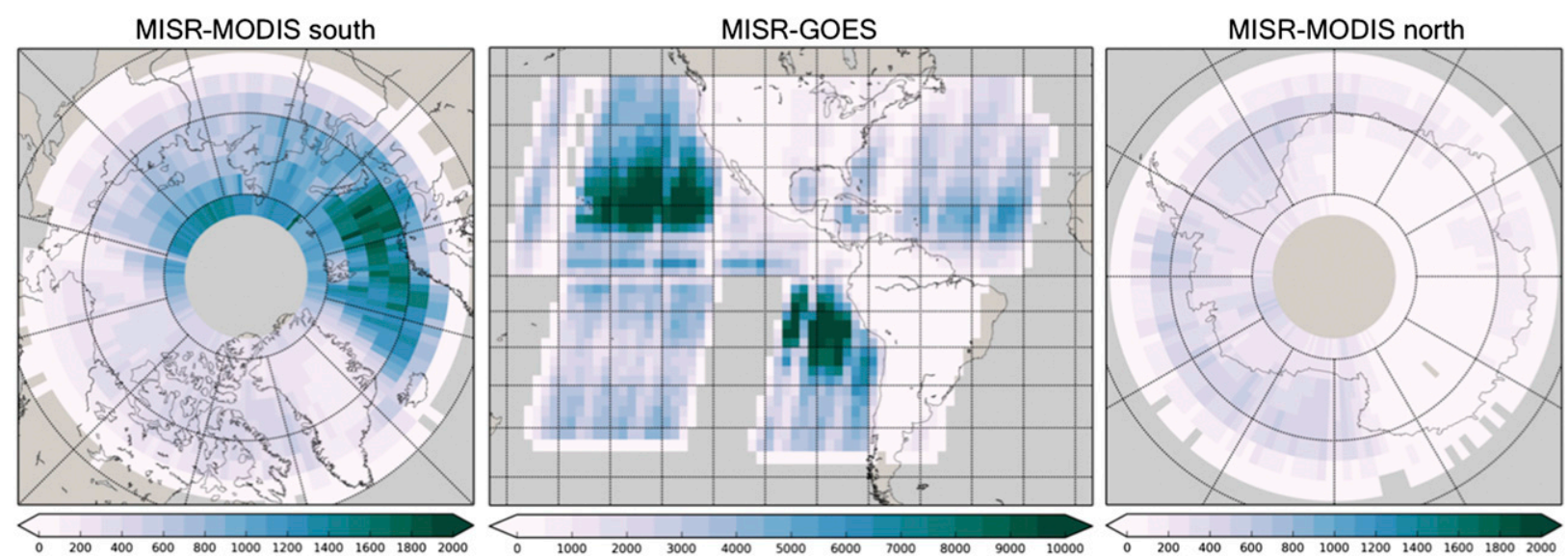

FIG. 7. Map of normalized samples per latitude-longitude bin for collocations between MISR CMV and (left) South Polar MODIS AMV, (center) GOES AMV, and (right) North Polar GOES AMV. Heights are required to agree within $1.5 \mathrm{~km}$ to eliminate the effects of tracking mismatches in multilayer cloud scenes. Pairs with LMATD $\left(>10 \mathrm{~m} \mathrm{~s}^{-1}\right)$ are also excluded (see Fig. 8). 

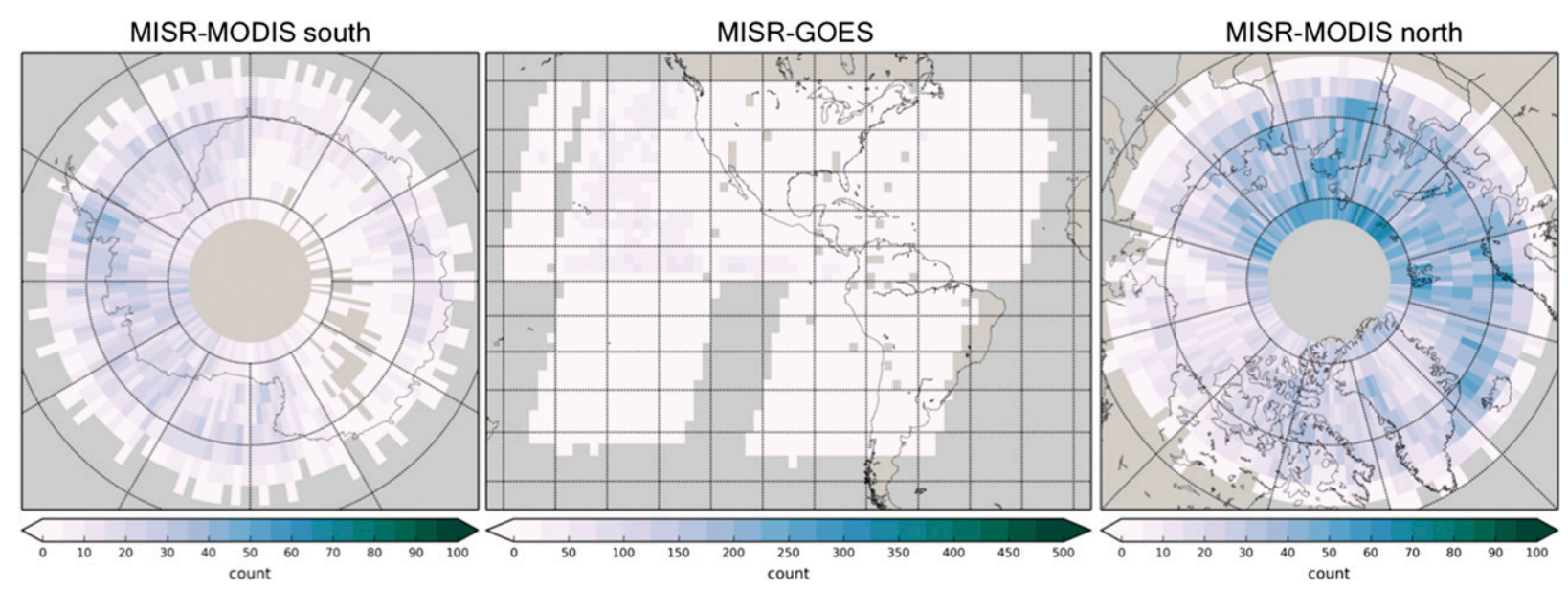

FIG. 8. As in Fig. 7, but for LMATD collocations only. Note the $\times 20$ reduction in the range of the color scale relative to Fig. 7 .

America. These regions also have the greatest frequency of cloud cover (e.g., Klein and Hartmann 1993). The MISR-MODIS maps in Fig. 7a (Antarctic) and Fig. 7c (Arctic) similarly show more frequent matches over the ocean than over the nearby landmasses.

Because of the statistical importance of LMATDs, they are mapped separately in Fig. 8. The maps in Fig. 8 show that for both the MODIS and GOES collocations, there is no particular pattern to the distribution of LMATDs. In the case of MODIS, the distribution of LMATD follows the distribution of overall sampling for non-LMATDs shown in Fig. 7. A survey of LMATD instances identified many cases where MISR and GOES both reported high speeds but with slightly different directions. Still, the frequency and character of LMATDs suggest there is some underlying source of gross error in the CMV retrieval (at the 5\% level) contributing to their presence. This source of error warrants further investigation, but its impact can and should be mitigated by screening CMVs relative to independent estimates of along-track wind, such as from a model.

Latitude-height distributions of collocated pairs of MISR-GOES and MISR-MODIS excluding height differences greater than $2.5 \mathrm{~m} \mathrm{~s}^{-1}$ and LMATD are presented in Fig. 9. For comparisons with MODIS AMVs, the latitude bins are sorted by whether the observations were acquired on the ascending or descending nodes of the Terra orbit. The $x$ axis in Figs. 9a and 9c accounts for the instrument sampling across both nodes, with the extreme latitude placed in the center of the plot. Because the solar zenith angle increases toward the left edge of Fig. 9a and the right edge of Fig. 9c, the number of days annually during which there is sufficient daylight for MISR CMV retrievals decreases in these directions, affecting the sampling.
Consistent with MISR CMV sampling in general, and Fig. 7b, the overwhelming majority of MISR-GOES collocations in Fig. 9b are associated with low-level marine stratocumulus clouds. The proclivity of the CMV retrieval to track stratiform clouds over ocean is further reflected in the sampling of MISR-MODIS collocations as well, most of which are found over open ocean in the Arctic (Fig. 9c). At high latitudes, MISR-MODIS collocations, and to a lesser extent MISR-GOES collocations, have a broader range of vertical sampling stemming from a greater prevalence of cloud types other than lowlevel stratocumulus.

\section{f. Zonal mean distribution of MISR CMV differences relative to collocated and filtered GOES and MODIS AMVS}

Figure 10 presents the latitude-height distributions of the differences between MISR CMVs and MODIS and GOES AMVs in terms of height (Figs. 10a-c), along-track component of the wind (Figs. 10d-f), and cross-track component of the wind (Figs. 10g-i). As in Fig. 9, the paired differences include only those with CMV-AMV height differences less than $1.5 \mathrm{~km}$ and along-track differences less than $10 \mathrm{~m} \mathrm{~s}^{-1}$ in order to diminish the respective roles of tracking mismatches and LMATDs.

The patterns of along-track and cross-track differences with respect to CMV height among MISR-GOES and MISR-MODIS wind collocations shown in Figs. 2-6 are broadly consistent over a range of latitudes. A gradient of MISR-GOES height differences for low-level clouds in Fig. 10b is mirrored by a similar gradient in along-track differences in Fig. 10e. In this case, uncertainty in the MISR retrieval is broadening the 

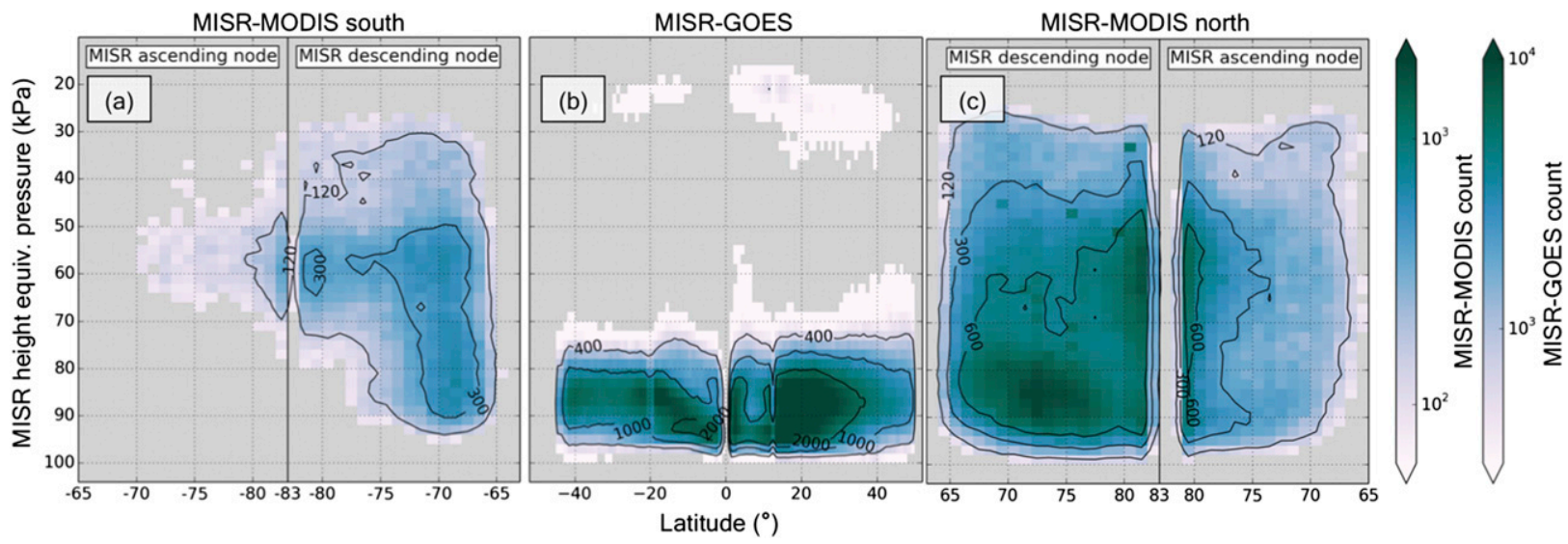

FIG. 9. Latitude-height distribution of count $N$ per $1^{\circ} \times 2 \mathrm{kPa}$ bin for collocations between MISR CMVs and (a) South Polar MODIS AMVs, (b) GOES AMVs, and (c) North Polar GOES AMVs. Contours are drawn in (a) and (c) for $N=120,300$, and 600 and in (b) for $N=400,1000$, and 2000. Comparisons with MODIS are segregated with respect to whether the MISR CMV was observed during the satellite ascending or descending node.

distribution of retrieved CMV heights, producing a gradient of both height and along-track differences relative to GOES as a function of height, modulated by sampling. MISR-GOES height and along-track differences are negligible around $90 \mathrm{kPa}$ where sampling is most dense but grow as large as $\pm 12 \mathrm{kPa}$ and $\pm 6 \mathrm{~m} \mathrm{~s}^{-1}$ toward the outer fringes of sampling around 95 and $75 \mathrm{kPa}$. There is little variation with latitude in these gradients except in the vicinity of the intertropical convergence zone (ITCZ). For higher clouds, MISR-GOES along-track differences also exhibit a gradient with height in the $35-15-\mathrm{kPa}$ height range. However, this upper-level along-track difference gradient has no corresponding height difference gradient. Instead, the CMV heights are consistently above the GOES AMV heights.

A smaller along-track difference gradient is apparent among the lower-latitude, Northern Hemisphere MISR-MODIS collocations shown in Fig. 10f. MISRMODIS collocations exhibit a consistent gradient of increasing height differences (Figs. 10a and 10c) that echoes Fig. 5a and was discussed in detail in section 3c. That gradient changes little with latitude for retrievals above $60 \mathrm{kPa}$. For lower-level winds, the lower-latitude height differences are not much different from those of the MISR-GOES collocations. At higher latitudes, there is a rapid transition toward larger height discrepancies south of $73^{\circ} \mathrm{S}$ and north of $75^{\circ} \mathrm{N}$. This is likely due to increasing prevalence of ice, which alters the cloud regime and affects the accuracy of MODIS low-level AMV height assignments.

In the Arctic (Fig. 10f), MISR-MODIS collocations show a broadly consistent along-track difference of $\sim 1 \mathrm{~m} \mathrm{~s}^{-1}$ at nearly all latitudes and levels except where an infrequently sampled low-level along-track bias gradient is evident, while in the Antarctic (Fig. 10d), the along-track difference increases systematically with height, from 1 to $5 \mathrm{~m} \mathrm{~s}^{-1}$. In both the Arctic and Antarctic, mean differences are smaller for the ascending node CMV retrievals, suggesting possible sensitivity to solar or viewing zenith angle.

Relative to the along-track components, the CMV cross-track components show better agreement with the AMV results. The mean cross-track differences relative to GOES AMV in Fig. 10h are consistently within $0.5 \mathrm{~m} \mathrm{~s}^{-1}$ except for locations where sampling is poor and a region around the ITCZ where differences are larger but still within $1.5 \mathrm{~m} \mathrm{~s}^{-1}$. The mean cross-track differences relative to MODIS in Figs. 10g and 10i are consistently within $1.5 \mathrm{~m} \mathrm{~s}^{-1}$. More significantly, the differences with magnitude greater than $0.5 \mathrm{~m} \mathrm{~s}^{-1}$ can be traced back to a cluster of tracking mismatches identified by label 7 in Fig. 5f. Those mismatches consist of MISR CMV at heights below collocated MODIS AMV where the lower wind has a larger northward component even when the height difference is within the $1.5-\mathrm{km}$ threshold employed here. This larger northward component translates to a lesser (greater) cross-track component during the MISR descending (ascending) node, which is what causes the mirroring of crosstrack differences with respect to the terminator (latitude $83^{\circ} \mathrm{N}-\mathrm{S}$ ) evident in Figs. $10 \mathrm{~g}$ and $10 \mathrm{i}$. Because most sampling occurs during the descending node, label (7) is associated with a negative cross-track difference in Fig. 5f.

Finally, a map of mean height and vector differences for MISR-GOES collocations is shown in Fig. 11. Again, the retrievals are vertically collocated to within $1.5 \mathrm{~km}$ and LMATDs are excluded. The only variability 


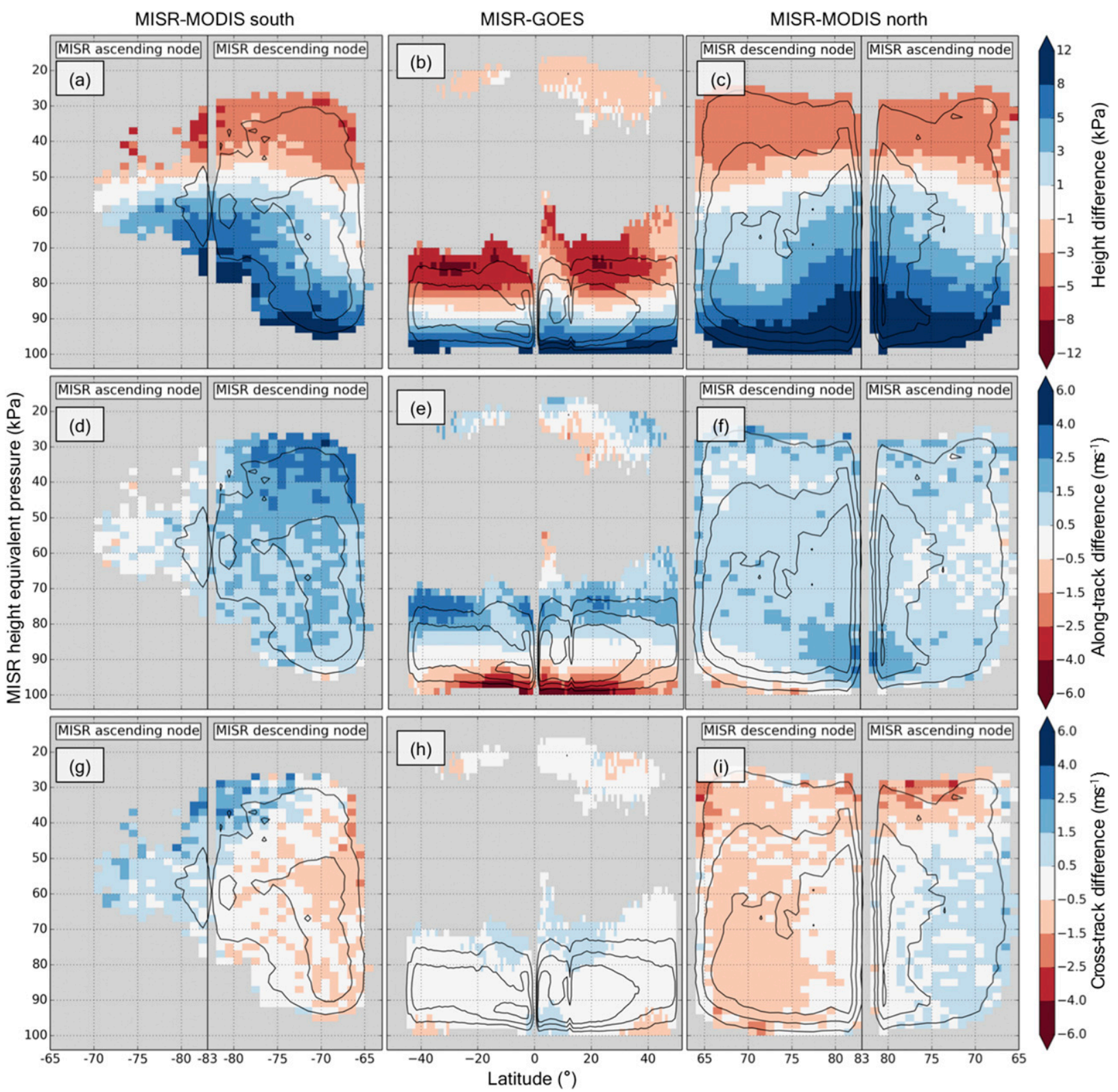

FIG. 10. Latitude-height distributions as in Fig. 9, but showing differences between MISR CMVs and MODIS or GOES AMVs for (a)-(c) reported wind height, (d)-(f) along-track wind component, and (g)-(i) cross-track wind component.

evident is where sampling is limited, which is the case for most collocations over land (see Fig. 7 center). The only region over land with enhanced sampling is the eastern United States, which shows differences consistent with collocations over ocean at similar latitude. Over northern South America, there is a pattern of differences noteworthy for its directional consistency that may be due to tracking mismatches, given the magnitude of height differences. Reviewing maps of MISR-MODIS collocations (not shown), one similarly finds limited regional variability that is insignificant relative to the magnitude of consistent alongtrack differences.

\section{g. Statistics of differences between MISR CMVs and GOES and MODIS AMVs stratified by quality indicator}

Tables 3 and 4 present mean and RMS differences between collocated MISR CMVs and GOES AMVs with height differences less than $1.5 \mathrm{~km}$ and LMATDs removed. Statistics are stratified by MISR-retrieval quality. Retrievals with QI $<50$ are excluded from the 


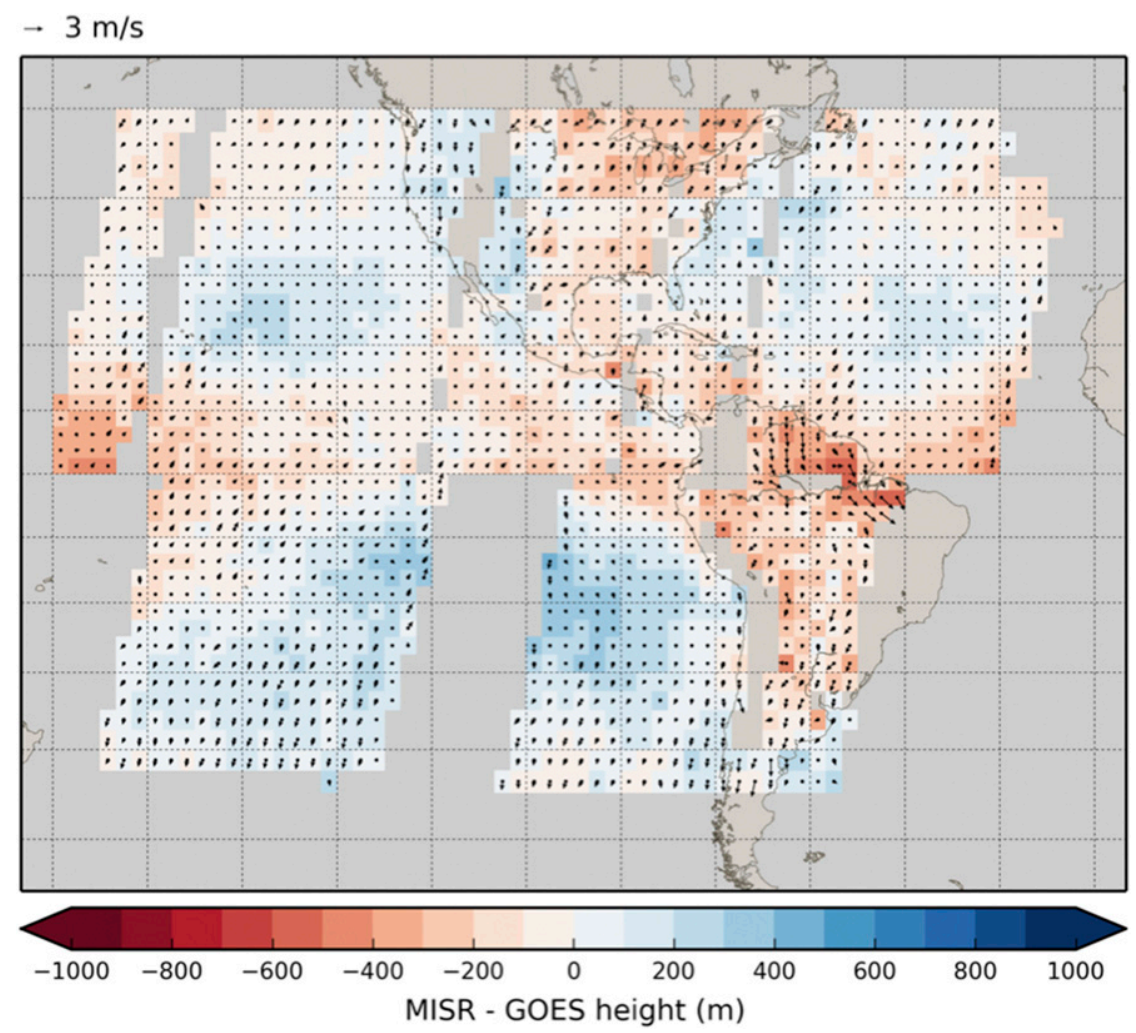

FIG. 11. Map of mean height and horizontal motion differences among collocated MISR CMVs and GOES AMVs. Associated sampling is shown in the center panel of Fig. 7.

comparison. Of those remaining, lower-quality retrievals have $50 \leq$ QI $<80$ and higher-quality retrievals have $\mathrm{QI} \geq 80$. The MISR-GOES collocations are separated into GOES VIS and IR channel groups. The IR collocations are also stratified by MISR height-equivalent pressure (low, mid-, and high level with respective pressure ranges of $70-100,40-70$, and $1-40 \mathrm{kPa}$ ). No such stratification is applied for VIS collocations, of which $99 \%$ are low level.

Among MISR-GOES collocations, differences associated with inexact collocation, tracking mismatches, and representativeness appear to be well constrained relative to the error associated with CMV retrieval uncertainty, as evidenced by the fact that along-track RMS differences are greater than cross-track differences throughout the MISR-GOES comparison. In this sense, MISR-GOES difference statistics appear to represent the accuracy of CMVs (and GOES AMVs). The percentage of LMATDs excluded in the MISR-GOES comparisons is insignificant except for the case of lowerquality CMVs paired with high-level IR AMVs (Table 4). Increasing the QI threshold reduces the contribution of LMATDs in all the IR comparisons by about a factor of 2 but does not eliminate them.
Low-level CMVs represent $95 \%$ of all collocations with GOES AMV, of which $86 \%$ are VIS and $14 \%$ IR channel. They exhibit a VRMS difference of $3.2 \mathrm{~m} \mathrm{~s}^{-1}$ for the highest-quality MISR retrievals with $\mathrm{QI} \geq 80$ and $3.4 \mathrm{~m} \mathrm{~s}^{-1}$ for all. This result is substantially smaller than the VRMS difference between low-level GOES AMV and collocated NOAA wind profiler measurements $\left(5.9 \mathrm{~m} \mathrm{~s}^{-1}\right)$ reported by Bedka et al. (2009). The discrepancy may be due to error in height assignment factoring into the GOES-profiler assessment but not the MISR-GOES assessment.

Midlevel CMVs account for 7\% of collocations with GOES IR channel AMV retrievals. Retrieval differences exhibit VRMS values ranging from 4.1 to $4.6 \mathrm{~m} \mathrm{~s}^{-1}$, depending on applied QI threshold. Those with QI $\geq$ 80 exhibit insignificant mean along-track differences. These higher-quality midlevel collocations make up $29 \%$ of the total, exhibiting a VRMS of $4.1 \mathrm{~m} \mathrm{~s}^{-1}$. High-level CMVs account for $18 \%$ of collocations with GOES IR AMVs. While they exhibit a mean along-track difference of $0.5 \mathrm{~m} \mathrm{~s}^{-1}$, those with $\mathrm{QI} \geq 80$ exhibit negligible alongtrack or cross-track bias and have a VRMS of $4.5 \mathrm{~m} \mathrm{~s}^{-1}$.

The difference statistics for the MISR-MODIS collocations appear to be dominated by more frequent 
TABLE 3. Statistics from comparison of MISR CMV with GOES VIS channel AMV (all levels).

\begin{tabular}{lcc}
\hline \hline & QI $\geq 50$ & QI $\geq 80$ \\
\hline No. of collocations $\times 10^{3}$ & 4305 & 1941 \\
Percent of LMATD excluded & 0.9 & 0.6 \\
Mean MISR height $(\mathrm{km})$ & 1.4 & 1.3 \\
Mean MISR speed $\left(\mathrm{m} \mathrm{s}^{-1}\right)$ & 9.6 & 9.4 \\
Height diff $\pm 1 \sigma(\mathrm{km})$ & $0.0 \pm 0.6$ & $0.0 \pm 0.6$ \\
Along-track diff $\pm 1 \sigma\left(\mathrm{m} \mathrm{s}^{-1}\right)$ & $0.1 \pm 2.9$ & $0.0 \pm 2.7$ \\
Cross-track diff $\pm 1 \sigma\left(\mathrm{m} \mathrm{s}^{-1}\right)$ & $0.1 \pm 1.7$ & $0.1 \pm 1.6$ \\
Vector RMS $\left(\mathrm{m} \mathrm{s}^{-1}\right)$ & 3.4 & 3.2 \\
\hline
\end{tabular}

tracking mismatches as reflected by larger height and motion differences relative to the MISR-GOES comparisons. Tables 5 and 6 show statistics for MISR-MODIS collocations for the Arctic and Antarctic regions, respectively. In these comparisons, ascending node retrievals are omitted. LMATDs are more frequent among MISR-MODIS low- and midlevel collocations, ranging from $5 \%$ to $9 \%$ depending on region, QI, and height. However, LMATDs are most commonly observed among high-level collocations, with a frequency of $22 \%$ in the Arctic and $24 \%$ in the Antarctic. These frequencies do not diminish significantly when excluding MISR CMV with QI $<80$, suggesting that many, if not most, of the LMATDs are not associated with gross MISR CMV error. Rather, many of these collocations are in the vicinity of jet streams, where large magnitudes of difference may arise from small differences in retrieval height or time or location of collocated observation.

Low- and midlevel MISR-MODIS collocations account for $90 \%$ of MISR-MODIS comparisons, exhibiting similar difference statistics in both the Arctic and Antarctic, with slightly smaller VRMS values in the Arctic. High-level MISR-MODIS collocations account for $10 \%$ of these collocations, exhibiting VRMS differences of $7.4 \mathrm{~m} \mathrm{~s}^{-1}$ in the Arctic and $8.1 \mathrm{~m} \mathrm{~s}^{-1}$ in the Antarctic with no reduction in VRMS for CMV with higher QI. MISR-MODIS VRMS differences are moderately less than VRMS differences between MODIS and rawinsonde $\left(6-9 \mathrm{~m} \mathrm{~s}^{-1}\right)$, estimated from an earlier study by Key et al. (2003) by multiplying the normalized VRMS by the mean speed.

\section{Conclusions}

Cloud motion vectors retrieved from the MISR instrument occupy a unique niche relative to the atmospheric motion vectors derived from other satellite instruments. Strengths of MISR CMVs include nearglobal sampling, an observational record dating back to 2000, and fine spatiotemporal resolution. The headline feature of the MISR approach is joint retrieval of geometric cloud height and cloud motion, which is responsible for different sampling and error characteristics relative to AMVs obtained by tracking cloud features and then assigning to them heights retrieved by radiometric means. These sampling differences include a greater preponderance of low-level winds in the MISR record. The prevalence of tracking mismatches between MISR CMVs and GOES or MODIS AMVs further demonstrates their differences in sampling, which represent synergy between traditional satellite-derived AMVs and CMVs from MISR and potential multiangle instruments with similar capabilities.

Within a high-quality subset where differences in retrieved heights were constrained to within $1.5 \mathrm{~km}$, collocated MISR-GOES winds show well-constrained and unbiased global differences (VRMS ranging from 3.3 to $4.5 \mathrm{~m} \mathrm{~s}^{-1}$ with height). This subset excludes MISR CMVs with lower quality $(\mathrm{QI}<80)$ and collocations with along-track differences greater than $10 \mathrm{~m} \mathrm{~s}^{-1}$ that appear to be associated with infrequent $(0.6 \%)$ large magnitude along-track errors in the MISR CMV retrieval. Within this subset, the greater accuracy of the MISR CMV cross-track component (RMS $\left.1.6 \mathrm{~m} \mathrm{~s}^{-1}\right)$ is evident relative to the along-track component (RMS $2.7 \mathrm{~m} \mathrm{~s}^{-1}$ ), reflecting expected MISR error characteristics.

TABLE 4. Statistics from comparison of MISR CMV with GOES IR channel AMV.

\begin{tabular}{|c|c|c|c|c|c|c|c|c|}
\hline & \multicolumn{2}{|c|}{ Low $(70-100 \mathrm{kPa})$} & \multicolumn{2}{|c|}{ Mid $(40-70 \mathrm{kPa})$} & \multicolumn{2}{|c|}{$\operatorname{High}(0-40 \mathrm{kPa})$} & \multicolumn{2}{|c|}{ All levels } \\
\hline & $\mathrm{QI} \geq 50$ & $\mathrm{QI} \geq 80$ & $\mathrm{QI} \geq 50$ & $\mathrm{QI} \geq 80$ & $\mathrm{QI} \geq 50$ & $\mathrm{QI} \geq 80$ & $\mathrm{QI} \geq 50$ & $\mathrm{QI} \geq 80$ \\
\hline No. of collocations $\times 10^{3}$ & 545 & 226 & 48 & 14 & 131 & 21 & 724 & 263 \\
\hline Percent of LMATD excluded & 0.4 & 0.2 & 3.5 & 1.4 & 7.3 & 3.2 & 2.0 & 0.6 \\
\hline Mean MISR height (km) & 1.5 & 1.5 & 5.3 & 5.2 & 10.6 & 10.2 & 3.7 & 2.6 \\
\hline Mean MISR speed $\left(\mathrm{m} \mathrm{s}^{-1}\right)$ & 9.8 & 9.7 & 14.6 & 14.2 & 20.0 & 20.9 & 12.2 & 11.1 \\
\hline Height diff $\pm 1 \sigma(\mathrm{km})$ & $0.2 \pm 0.6$ & $0.2 \pm 0.5$ & $0.1 \pm 0.8$ & $0.1 \pm 0.8$ & $0.3 \pm 0.7$ & $0.3 \pm 0.7$ & $0.2 \pm 0.6$ & $0.2 \pm 0.6$ \\
\hline Along-track diff $\pm 1 \sigma\left(\mathrm{m} \mathrm{s}^{-1}\right)$ & $0.2 \pm 2.8$ & $0.2 \pm 2.6$ & $0.5 \pm 3.7$ & $0.1 \pm 3.3$ & $0.5 \pm 4.2$ & $0.1 \pm 3.8$ & $0.3 \pm 3.2$ & $0.1 \pm 2.8$ \\
\hline Cross-track diff $\pm 1 \sigma\left(\mathrm{m} \mathrm{s}^{-1}\right)$ & $0.0 \pm 1.6$ & $0.0 \pm 1.5$ & $0.1 \pm 2.5$ & $0.1 \pm 2.4$ & $0.0 \pm 2.5$ & $-0.1 \pm 2.5$ & $0.0 \pm 1.9$ & $0.0 \pm 1.7$ \\
\hline Vector RMS $\left(\mathrm{m} \mathrm{s}^{-1}\right)$ & 3.2 & 3.0 & 4.5 & 4.1 & 4.9 & 4.5 & 3.7 & 3.3 \\
\hline
\end{tabular}


TABLE 5. Statistics from comparison of MISR CMV with Arctic MODIS IR channel AMV.

\begin{tabular}{|c|c|c|c|c|c|c|c|c|}
\hline & \multicolumn{2}{|c|}{ Low $(70-100 \mathrm{kPa})$} & \multicolumn{2}{|c|}{ Mid $(40-70 \mathrm{kPa})$} & \multicolumn{2}{|c|}{ High $(0-40 \mathrm{kPa})$} & \multicolumn{2}{|c|}{ All levels } \\
\hline & $\mathrm{QI} \geq 50$ & $\mathrm{QI} \geq 80$ & $\mathrm{QI} \geq 50$ & $\mathrm{QI} \geq 80$ & $\mathrm{QI} \geq 50$ & $\mathrm{QI} \geq 80$ & $\mathrm{QI} \geq 50$ & $\mathrm{QI} \geq 80$ \\
\hline No. ${ }^{\text {a }}$ of collocations $\times 10^{3}$ & $236(66)$ & 103 (29) & 194 (91) & $65(34)$ & 37 (17) & $5(3)$ & 468 (174) & $174(66)$ \\
\hline Percent of LMATD excluded & 5.6 & 3.8 & 7.7 & 4.5 & 21.7 & 16.7 & 7.9 & 4.6 \\
\hline Mean MISR height (km) & 1.6 & 1.6 & 4.5 & 4.4 & 8.3 & 8.2 & 3.4 & 3.0 \\
\hline Mean MISR speed $\left(\mathrm{m} \mathrm{s}^{-1}\right)$ & 10.1 & 10.0 & 13.2 & 12.7 & 21.8 & 22.4 & 12.3 & 11.5 \\
\hline Height diff $\pm 1 \sigma(\mathrm{km})$ & $-0.5 \pm 0.6$ & $-0.5 \pm 0.6$ & $-0.1 \pm 0.7$ & $-0.2 \pm 0.6$ & $0.5 \pm 0.7$ & $0.5 \pm 0.7$ & $-0.2 \pm 0.7$ & $-0.3 \pm 0.7$ \\
\hline Along-track diff $\pm 1 \sigma\left(\mathrm{m} \mathrm{s}^{-1}\right)$ & $1.1 \pm 3.8$ & $1.0 \pm 3.6$ & $1.1 \pm 4.0$ & $1.1 \pm 3.8$ & $1.3 \pm 4.9$ & $1.2 \pm 4.8$ & $1.1 \pm 4.0$ & $1.1 \pm 3.7$ \\
\hline Cross-track diff $\pm 1 \sigma\left(\mathrm{m} \mathrm{s}^{-1}\right)$ & $-0.6 \pm 3.6$ & $-0.5 \pm 3.5$ & $-0.5 \pm 3.7$ & $-0.5 \pm 3.5$ & $-0.9 \pm 5.4$ & $-0.8 \pm 5.5$ & $-0.6 \pm 3.8$ & $-0.5 \pm 3.6$ \\
\hline Vector RMS $\left(\mathrm{m} \mathrm{s}^{-1}\right)$ & 5.4 & 5.1 & 5.6 & 5.3 & 7.4 & 7.4 & 5.6 & 5.3 \\
\hline
\end{tabular}

${ }^{a}$ Number of collocations for ascending node indicated in parentheses.

The role of height assignment error was assessed by identifying collocations where mean differences in cloud motion between MISR CMVs and GOES AMVs were less than would be expected on the basis of differences in retrieved height, using MERRA reanalysis to indicate where vertical wind shear is significant. Echoing earlier studies, about $37 \%$ of GOES AMVs at heights in the 2-4-km range under such conditions are incorrectly assigned heights as much as $3 \mathrm{~km}$ higher than their collocated MISR counterparts. On the other hand, about $25 \%$ of MISR CMVs at heights in the $10-13-\mathrm{km}$ range were assigned heights up to $2 \mathrm{~km}$ higher than their GOES counterparts. These CMVs with overestimated heights were part of a wider pattern of MISR CMV retrievals that exhibited both positive height bias and positive along-track bias relative to GOES, consistent with the expected correlation of error in these parameters for the MISR retrieval. This correlation also produced prominent and globally consistent systematic gradients of along-track bias with respect to height among MISR CMVs. Interpretation of such gradients is complicated by the fact that collocated MISR CMV sampling cannot be guaranteed to be unbiased as a function of height. Including MISR CMVs with lower QI value in the assessment of MISR-GOES collocations results in little change to the VRMS differences but reduces mean along-track bias to $0.5 \mathrm{~m} \mathrm{~s}^{-1}$ among midand high-level $(<70 \mathrm{kPa})$ collocations.

This study also evaluated collocations of MISR CMVs and MODIS AMVs over the same 6-yr period. Relative to the MISR-GOES comparison, the MISR-MODIS results show less well-constrained and more biased global differences. However, there is strong evidence that those differences are driven by a greater frequency of tracking mismatches where cloud motions at distinct heights in a multilayer scene are compared. Relative to the Antarctic, the Arctic exhibits greater sampling and generally smaller biases and RMS differences between MISR and MODIS. There, low- and midlevel ( $\geq 40 \mathrm{kPa})$ collocations exhibit a VRMS of $5.2 \mathrm{~m} \mathrm{~s}^{-1}$ and a mean bias of $1.1 \mathrm{~m} \mathrm{~s}^{-1}$, largely irrespective of QI threshold. High-level collocations exhibit similar bias but larger VRMS.

On the whole, broad consistency is found between MISR CMVs and collocated GOES and MODIS AMVs, despite evident patterns of difference. Preliminary studies have demonstrated positive forecast impact of assimilated MISR CMVs, where benefits stem from MISR's sampling of the high-latitude gap in AMV observations and from the dense sampling of low-level winds. This result is consistent with the findings of this

TABLE 6. Statistics from comparison of MISR CMV with Antarctic MODIS IR channel AMV.

\begin{tabular}{|c|c|c|c|c|c|c|c|c|}
\hline & \multicolumn{2}{|c|}{ Low (70-100 kPa) } & \multicolumn{2}{|c|}{ Mid $(40-70 \mathrm{kPa})$} & \multicolumn{2}{|c|}{$\operatorname{High}(0-40 \mathrm{kPa})$} & \multicolumn{2}{|c|}{ All levels } \\
\hline & $\mathrm{QI} \geq 50$ & $\mathrm{QI} \geq 80$ & $\mathrm{QI} \geq 50$ & $\mathrm{QI} \geq 80$ & $\mathrm{QI} \geq 50$ & $\mathrm{QI} \geq 80$ & $\mathrm{QI} \geq 50$ & $\mathrm{QI} \geq 80$ \\
\hline No. ${ }^{\mathrm{a}}$ of collocations $\times 10^{3}$ & $50(6)$ & $23(3)$ & $85(21)$ & $34(9)$ & $19(5)$ & $5(1)$ & $155(32)$ & $63(14)$ \\
\hline Percent of LMATD excluded & 6.8 & 5.0 & 8.9 & 6.3 & 24.1 & 21.4 & 10.1 & 7.2 \\
\hline Mean MISR height (km) & 1.5 & 1.5 & 4.2 & 4.1 & 7.8 & 7.7 & 3.7 & 3.4 \\
\hline Mean MISR speed $\left(\mathrm{m} \mathrm{s}^{-1}\right)$ & 10.2 & 9.8 & 12.6 & 11.9 & 23.4 & 23.4 & 12.9 & 12.0 \\
\hline Height diff $\pm 1 \sigma(\mathrm{km})$ & $-0.5 \pm 0.6$ & $-0.4 \pm 0.6$ & $-0.2 \pm 0.7$ & $-0.2 \pm 0.6$ & $0.6 \pm 0.7$ & $0.6 \pm 0.7$ & $-0.1 \pm 0.7$ & $-0.2 \pm 0.7$ \\
\hline Along-track diff $\pm 1 \sigma\left(\mathrm{m} \mathrm{s}^{-1}\right)$ & $1.3 \pm 3.8$ & $1.1 \pm 3.6$ & $1.6 \pm 4.0$ & $1.5 \pm 3.8$ & $2.6 \pm 4.7$ & $2.6 \pm 4.6$ & $1.6 \pm 4.0$ & $1.1 \pm 3.8$ \\
\hline Cross-track diff $\pm 1 \sigma\left(\mathrm{m} \mathrm{s}^{-1}\right)$ & $-0.3 \pm 3.8$ & $-0.4 \pm 3.7$ & $-0.4 \pm 4.1$ & $-0.5 \pm 4.0$ & $0.3 \pm 6.1$ & $0.1 \pm 6.1$ & $-0.1 \pm 4.3$ & $-0.2 \pm 4.1$ \\
\hline Vector RMS $\left(\mathrm{m} \mathrm{s}^{-1}\right)$ & 5.5 & 5.3 & 6.0 & 5.7 & 8.1 & 8.0 & 6.1 & 5.8 \\
\hline
\end{tabular}

${ }^{\text {a }}$ Number of collocations for ascending node indicated in parentheses. 
study. Effective use of MISR CMVs for assimilation should account for the systematic biases related to the correlation between height and along-track error that this study has quantified. Reducing the influence of such biases, while exploiting the unique strengths of MISR, should benefit not only forecasts, but diagnostics of other sources of wind observations.

Acknowledgments. This research was carried out at Jet Propulsion Laboratory, California Institute of Technology, under contract with the National Aeronautics and Space Administration. The authors are indebted to the MISR team, particularly Earl Hansen and Roger Davies, for helpful advice throughout this study. Thoughtful suggestions from reviewers are also acknowledged.

\section{REFERENCES}

Baker, N. L., P. M. Pauley, R. H. Langland, K. Mueller, and D. Wu, 2014: An assessment of the impact of the assimilation of NASA Terra MISR atmospheric motion vectors on the NRL Global Atmospheric Prediction System. Second Symp. on the Joint Center for Satellite Data Assimilation, Atlanta, GA, Amer. Meteor. Soc., J3.1. [Available online at https://ams. confex.com/ams/94Annual/webprogram/Paper231106.html.]

Bedka, K. M., and J. R. Mecikalski, 2005: Application of satellitederived atmospheric motion vectors for estimating mesoscale flows. J. Appl. Meteor., 44, 1761-1772, doi:10.1175/ JAM2264.1.

- C. S. Velden, R. A. Petersen, W. F. Feltz, and J. R. Mecikalski, 2009: Comparisons of satellite-derived atmospheric motion vectors, rawinsondes, and NOAA Wind Profiler observations. J. Appl. Meteor. Climatol., 48, 1542-1561, doi:10.1175/2009JAMC1867.1.

Borde, R., O. Hautecoeur, and M. Carranza, 2016: EUMETSAT global AVHRR wind product. J. Atmos. Oceanic Technol., 133, 429-438, doi: 10.1175/JTECH-D-15-0155.1.

Cress, A., 2014: Assessment of MISR wind vector quality and impact using the global NWP system at DWD. 12th Int. Winds Workshop, Copenhagen, Denmark, European Organisation for the Exploitation of Meteorological Satellites, $7 \mathrm{pp}$. [Available online at http://www.eumetsat.int/website/wcm/ idc/idcplg? IdcService $=$ GET_FILE \&dDocName $=$ PDF CONF_P61_S4_02_CRESS_V\&RevisionSelectionMethod $=$ LatestReleased\&Rendition $=$ Web.]

Davies, R., Á. Horváth, C. Moroney, B. Zhang, and Y. Zhu, 2007: Cloud motion vectors from MISR using sub-pixel enhancements. Remote Sens. Environ., 107, 194-199, doi:10.1016/j.rse.2006.09.023.

Di Michele, S., T. McNally, P. Bauer, and I. Genkova, 2013: Quality assessment of cloud-top height estimates from satellite IR radiances using the CALIPSO lidar. IEEE Trans. Geosci. Remote Sens., 51, 2454-2464, doi:10.1109/TGRS.2012.2210721.

Garay, M. J., S. P. de Szoeke, and C. M. Moroney, 2008: Comparison of marine stratocumulus cloud top heights in the southeastern Pacific retrieved from satellites with coincident ship-based observations. J. Geophys. Res., 113, D18204, doi:10.1029/ 2008JD009975.

Hinkelman, L. M., R. T. Marchand, and T. P. Ackerman, 2009: Evaluation of Multiangle Imaging SpectroRadiometer cloud motion vectors using NOAA radar wind profiler data. J. Geophys. Res., 114, D21207, doi:10.1029/2008JD011107.
Holz, R.E., S. A. Ackerman, F. W. Nagle, R. Frey, S. Dutcher, R.E. Kuehn, M. A. Vaughan, and B. Baum, 2008: Global Moderate Resolution Imaging Spectroradiometer (MODIS) cloud detection and height evaluation using CALIOP. J. Geophys. Res., 113, D00A19, doi:10.1029/2008JD009837.

Horváth, Á., 2013: Improvements to MISR stereo motion vectors. J. Geophys. Res. Atmos., 118, 5600-5620, doi:10.1002/jgrd.50466. , and R. Davies, 2001: Feasibility and error analysis of cloud motion wind extraction from near-simultaneous multiangle MISR measurements. J. Atmos. Oceanic Technol., 18, 591-608, doi:10.1175/1520-0426(2001)018<0591:FAEAOC $>2.0 . C O ; 2$.

Jewett, C. P., and J. R. Mecikalski, 2010: Estimating convective momentum fluxes using geostationary satellite data. J. Geophys. Res., 115, D14104, doi:10.1029/2009JD012919.

Jovanovic, V., K. Miller, B. Rheingans, and C. Moroney, 2012: MISR science data product guide. JPL Tech. Doc. JPL D-73355, 36 pp. [Available online at https://eosweb.larc.nasa.gov/sites/ default/files/project/misr/guide/MISR_Science_Data_Product_ Guide.pdf.]

Key, J. R., D. Santek, C. S. Velden, N. Bormann, J.-N. Thepaut, L. P. Riishojgaard, Y. Zhu, and W. P. Menzel, 2003: Cloud-drift and water vapor winds in the polar regions from MODISIR. IEEE Trans. Geosci. Remote Sens., 41, 482-492, doi:10.1109/ TGRS.2002.808238.

Klein, S. A., and D. L. Hartmann, 1993: The seasonal cycle of low stratiform clouds. J. Climate, 6, 1587-1606, doi:10.1175/ 1520-0442(1993)006<1587:TSCOLS $>2.0 . \mathrm{CO} ; 2$.

Lazzara, M. A., R. Dworak, D. A. Santek, B. T. Hoover, C. S. Velden, and J. R. Key, 2014: High-latitude atmospheric motion vectors from composite satellite data. J. Appl. Meteor. Climatol. 53, 534-547, doi:10.1175/JAMC-D-13-0160.1.

Liu, J., and K. Mueller, 2014: Assimilation and evaluation of MultiAngle Imaging Spectrometer (MISR) cloud tracked winds with GEOS-5 operational data assimilation system. JCSDA Quarterly, No. 46, 7-8. [Available online at https://www.star.nesdis.noaa. gov/jcsda/documents/newsletters/2014_02JCSDAQuarterly.pdf.]

Lonitz, K., and Á. Horváth, 2011: Comparison of MISR and Meteosat-9 cloud-motion vectors. J. Geophys. Res., 116, D24202, doi:10.1029/2011JD016047.

Marchand, R. T., T. P. Ackerman, and C. Moroney, 2007: An assessment of Multiangle Imaging SpectroRadiometer (MISR) stereo-derived cloud top heights and cloud top winds using ground-based radar, lidar, and microwave radiometers. J. Geophys. Res., 112, D06204, doi:10.1029/2006JD007091.

Mueller, K., C. Moroney, V. Jovanovic, M. J. Garay, J.-P. Muller, L. Di Girolamo, and R. Davies, 2013: MISR level 2 cloud product algorithm theoretical basis. JPL Tech. Doc. JPL D73327, 51 pp. [Available online at http://eospso.nasa.gov/sites/ default/files/atbd/MISR_L2_CLOUD_ATBD-1.pdf.]

— - V. Jovanovic, and C. Moroney, 2014: MISR cloud motion vector quality statement. Atmospheric Science Data Center Rep., 5 pp. [Available online at https://eosweb.larc.nasa.gov/sites/default/ files/project/misr/quality_summaries/L3_CMV_Product.pdf.]

Muller, J.-P., A. Mandanayake, C. Moroney, R. Davies, D. J. Diner, and S. Paradise, 2002: MISR stereoscopic image matchers: Techniques and results. IEEE Trans. Geosci. Remote Sens., 40, 1547-1559, doi:10.1109/TGRS.2002.801160.

Naud, C., J.-P. Muller, and E. E. Clothiaux, 2002: Comparison of cloud top heights derived from MISR stereo and MODIS $\mathrm{CO}_{2}$-slicing. Geophys. Res. Lett., 29, 1795, doi:10.1029/ 2002GL015460.

- — - M. Haeffelin, Y. Morille, and A. Delaval, 2004: Assessment of MISR and MODIS cloud top heights through 
inter-comparison with a back-scattering lidar at SIRTA. Geophys. Res. Lett., 31, L04114, doi:10.1029/2003GL018976.

E. E. Clothiaux, B. A. Baum, and W. P. Menzel, 2005: Intercomparison of multiple years of MODIS, MISR and radar cloud-top heights. Ann. Geophys., 23, 2415-2424, doi:10.5194/ angeo-23-2415-2005.

Nieman, S. J., J. Schmetz, and W. P. Menzel, 1993: A comparison of several techniques to assign heights to cloud tracers. J. Appl. Meteor., 32, 1559-1568, doi:10.1175/1520-0450(1993)032<1559: ACOSTT>2.0.CO;2.

, W. P. Menzel, C. M. Hayden, D. Gray, S. T. Wanzong, C. S. Velden, and J. Daniels, 1997: Full automated cloud-drift winds in NESDIS operations. Bull. Amer. Meteor. Soc., 78, 1121-1133, doi:10.1175/1520-0477(1997)078<1121:FACDWI >2.0.CO;2.

Rienecker, M. M., and Coauthors, 2011: MERRA: NASA's ModernEra Retrospective Analysis for Research and Applications. J. Climate, 24, 3624-3648, doi:10.1175/JCLI-D-11-00015.1.

Salonen, K., J. Cotton, N. Bormann, and M. Forsythe, 2015: Characterizing AMV height-assignment error by comparing best-fit pressure statistics from the Met Office and ECMWF data assimilation systems. J. Appl. Meteor. Climatol., 54, 225242, doi:10.1175/JAMC-D-14-0025.1.

Santek, D., 2010: The impact of satellite-derived polar winds on lowerlatitude forecasts. Mon. Wea. Rev., 138, 123-139, doi:10.1175/ 2009MWR2862.1.

Velden, C. S., and K. M. Bedka, 2009: Identifying the uncertainty in determining satellite-derived atmospheric motion vector height attribution. J. Appl. Meteor. Climatol., 48, 450-463, doi:10.1175/ 2008JAMC1957.1.
_- T. L. Olander, and S. Wanzong, 1998: The impact of multispectral GOES-8 wind information on Atlantic tropical cyclone track forecasts in 1995. Part I: Dataset methodology, description, and case analysis. Mon. Wea. Rev., 126, 1202-1218, doi:10.1175/1520-0493(1998)126<1202: TIOMGW>2.0.CO;2.

- , and Coauthors, 2005: Recent innovations in deriving tropospheric winds from meteorological satellites. Bull. Amer. Meteor. Soc., 86, 205-223, doi:10.1175/BAMS-86-2-205.

Wanzong, S., D. Santek, C. S. Velden, J. Daniels, D. Stettner, W. C. Bresky, and A. Bailey, 2014: Historical GOES AMV re-processing. 12th Int. Winds Workshop, Copenhagen, Denmark, European Organisation for the Exploitation of Meteorological Satellites, $6 \mathrm{pp}$. [Available online at http://www. eumetsat.int $/$ website $/ \mathrm{wcm} /$ idc/idcplg? IdcService $=\mathrm{GET}_{-}$ FILE\&dDocName $=$ PDF_CONF_P61_S10_02_WANZONG_ V\&RevisionSelectionMethod=LatestReleased\&Rendition $=$ Web.]

Yamashita, K, 2014: The impact of NASA TERRA MISR atmospheric motion vector assimilation into JMA's operational global NWP system. World Climate Research Programme Rep. 11/2014, 2 pp. [Available online at http://www.wcrp-climate.org/ WGNE/BlueBook/2014/individual-articles/01_Yamashita_Koji_ WGNE_BB2014_MISR_yamashita_final.pdf.]

Zong, J., R. Davies, J.-P. Muller, and D. J. Diner, 2002: Photogrammetric retrieval of cloud advection and top height from the Multi-angle Imaging SpectroRadiometer (MISR). Photogramm. Eng. Remote Sensing, 68, 821-829. [Available online at http://info.asprs.org/publications/pers/2002journal/august/ 2002_aug_821-829.pdf.] 